Supporting Information

\title{
Anionic Ring-Opening Polymerizations of $N$-Sulfonylaziridines in Ionic Liquids
}

Chandan Giri ${ }^{1}$, Sarah E. Sisk ${ }^{1}$, Louis Reisman ${ }^{1}$, Irshad Kammakakam², Jason E. Bara ${ }^{2}$, Kevin N. West $^{3}$, Brooks D. Rabideau ${ }^{3 *}$, Paul A. Rupar ${ }^{1 *}$

${ }^{1}$ Department of Chemistry \& Biochemistry, The University of Alabama, Tuscaloosa, Alabama 35487-0336, United States

${ }^{2}$ Department of Chemical and Biological Engineering, The University of Alabama, Tuscaloosa,

Alabama 35487-0336, United States

${ }^{3}$ Department of Chemical \& Biomolecular Engineering, The University of South Alabama,

Mobile, Alabama 36688, United States

parupar@ua.edu

brabideau@southalabama.edu

\section{TABLE OF CONTENTS}

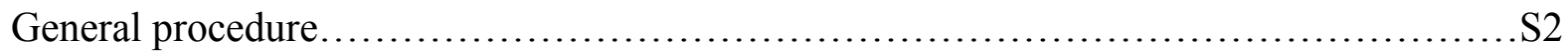

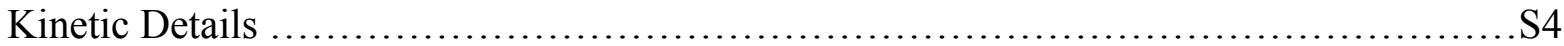

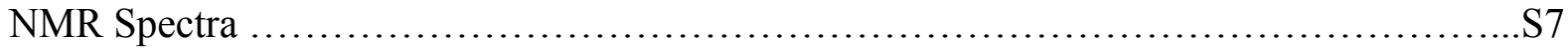

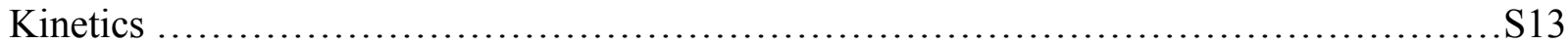

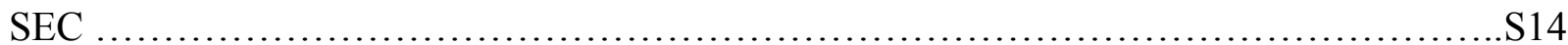


MALDI-TOF MS Spectra $\mathrm{S} 16$

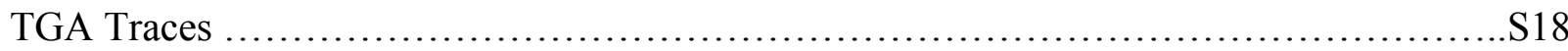

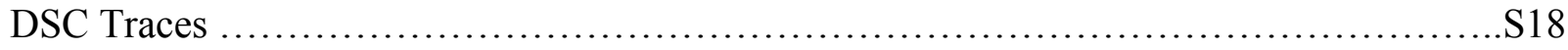

Molecular Dynamics Simulations........................................................... 19

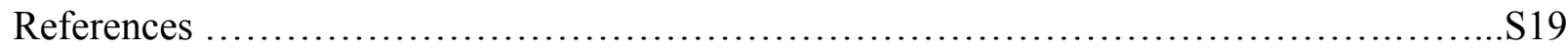

Molecular Dynamics Simulations:

All molecules were modeled using the General AMBER Force Field (GAFF) ${ }^{1}$. Partial atomic charges were determined using DFT in Gaussian $09^{2}$ using the $6-31 \mathrm{G}^{*}$ basis set and a scaling of $80 \%$ for all atoms to account for polarizability effects. The number of molecules within each simulation box was determined such that they would fit into a cubic box with side length of 65 Angstroms assuming ideal mixing. Since the initiator holds a negative charge, additional $\mathrm{K}+$ ions were added to ensure the charge neutrality of the system. The monomer to initiator ratio was fixed at 8 to 1 , the solvent concentration as $70 \mathrm{wt} \%$, and the system was packed using $\mathrm{PACKMOL}^{3}$. These proportions ensured that there would be sufficient initiator-monomer collisions during the simulation.

\section{General Experimental Procedures:}

All manipulations were carried out under an anhydrous $\mathrm{N}_{2}$ atmosphere using standard Schlenk line and glove box techniques. Solvents were purified by passing through an alumina column, degassed, and then stored over $3 \AA$ molecular sieves. Size exclusion chromatography (SEC) was performed using a Malvern Viscotek Gel Permeation Chromatograph equipped with an RI detector, an automatic sampler, a pump, an injector, an inline degasser, a column oven $\left(60{ }^{\circ} \mathrm{C}\right)$, and two in-series Malvern T6000M SEC columns. DMF was used as the mobile phase at a flow rate of $1 \mathrm{~mL} / \mathrm{min}$.

MALDI-TOF mass spectra were acquired on a Bruker rapifleX MALDI-TOF mass spectrometer. The polymer MALDI-TOF mass spectra were acquired in reflectron positive mode and samples were prepared using the dried-droplet method. Briefly, $2 \mu \mathrm{L}$ of polymer $(10 \mathrm{mg} / \mathrm{mL})$ in DMF was mixed with $10 \mu \mathrm{L}$ of DHB $(10 \mathrm{mg} / \mathrm{mL})$ in THF and $1 \mu \mathrm{L}$ of NaI $(10 \mathrm{mg} / \mathrm{mL})$ in THF. $1 \mu \mathrm{L}$ of this solution was spotted and allowed to dry. 
All the imidazolium ionic liquids were synthesized based on the literature procedure and dried under vacuum. For instance, 1-butyl-2,3-dimethyl imidazoliumbis(trifluoromethylsulfonyl)imide was synthesized as described below.

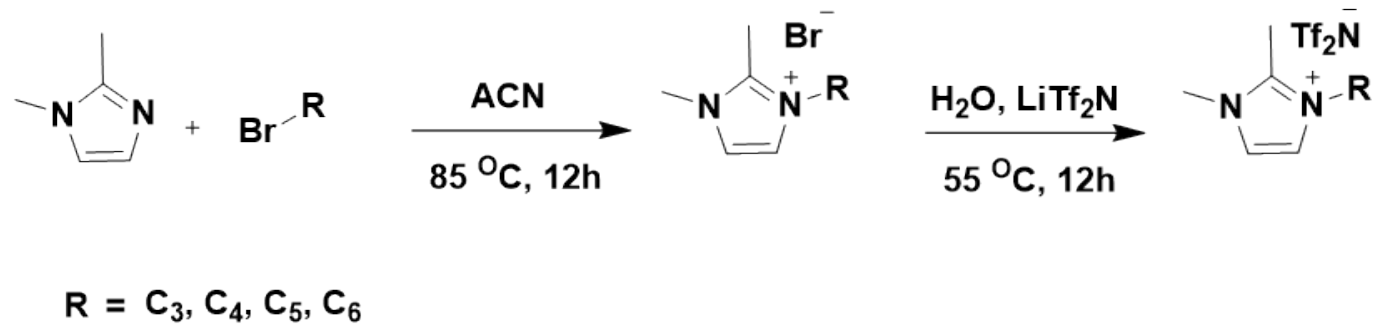

1,2-dimethylimidazole (40 g, $0.42 \mathrm{~mol}$ ) was combined with 1-bromobutane (62.71 g, $0.4577 \mathrm{~mol})$ and $250 \mathrm{~mL}$ of acetonitrile $(\mathrm{ACN})$ in a $500 \mathrm{~mL}$ pressure vessel fitted with a screw cap and Kalrez O-ring. The reaction mixture was then allowed to stir at $85^{\circ} \mathrm{C}$ for $12 \mathrm{~h}$. After this, the ACN solvent was removed under vacuum and the mixture was poured into diethyl ether and placed into the freezer to crystallize. The diethyl ether was decanted and the crystallized solid was then dissolved into $200 \mathrm{~mL}$ DI water. This solution was further washed with 3 x $200 \mathrm{~mL}$ of diethyl ether and $\operatorname{LiTf}_{2} \mathrm{~N}(179.2 \mathrm{~g}, 0.624 \mathrm{~mol})$ was added to this $\mathrm{H}_{2} \mathrm{O}$ solution after washing and allowed to stir at $55^{\circ} \mathrm{C}$ until an oily bottom layer formed. The water layer was decanted carefully, and the residual oil layer was dissolved in $250 \mathrm{~mL}$ DCM. Later, the DCM mixture was then washed with DI water ( $3 \times 100 \mathrm{~mL}$ ) and dried over anhydrous $\mathrm{MgSO}_{4}$. The resultant solution was filtered, and the DCM solvent was evaporated under reduced pressure at temperature $\leq 30^{\circ} \mathrm{C}$. Then, the colorless transparent oil was vacuum dried at ambient temperature for $12 \mathrm{~h}$ to obtain the final product.

$\left[\mathrm{P}_{6,6,6,14}\right]\left[\mathrm{NTf}_{2}\right]$ was purchased from either Acros (97\%) catalog no. 5090110418 or Sigma-Aldrich (95\%) batch no 50971. TsMAz did not polymerize successfully in $\left[\mathrm{P}_{6,6,6,14}\right]\left[\mathrm{NTf}_{2}\right]$ purchased from Sigma-Aldrich (95\%).

BuN(H)Ts ${ }^{4}$ was synthesized based on the literature procedure and purified by distillation at 120 ${ }^{\circ} \mathrm{C}$ and 50 mtorr. The TsMAz monomer was synthesized according to literature and purified by column chromatography. ${ }^{5}$ 


\section{Polymerization Procedures}

All polymerizations were performed using the same procedure, except that the ratio of the monomers to initiator, reaction time, and concentration were varied. The example procedure below has a monomers:initiator of 60:1 A stock solution of $\mathbf{B u N}(\mathbf{K})$ Ts in anhydrous DMF was prepared by combining KHMDS (54.0 mg, $0.270 \mathrm{mmol})$ and BuN(H)Ts (62 mg, $0.270 \mathrm{mmol})$ in DMF (2 $\mathrm{mL}$ ). This solution was allowed to stir for $1 \mathrm{~h}$ at room temperature. The resulting solution of ${ }^{n} \mathrm{BuN}(\mathrm{K}) \mathrm{Ts}$ in DMF was used without any further characterization or purification.

To $\left[\mathrm{P}_{6,6,6,14}\right]\left[\mathrm{NTf}_{2}\right]$ IL commercial Acros 97\% (0.65 mL) was added TsMAz ${ }^{6}$ (74 mg, 0.35 mmol). To this solution was added a portion of the prepared ${ }^{n} \mathrm{BuN}(\mathrm{K}) \mathrm{Ts}$ in solution $(0.44 \mathrm{~mL}, 0.060$ $\mathrm{mmol})$. The reaction mixture was stirred for $12 \mathrm{~h}$ at different temperature. Upon cooling to room temperature, the reaction was precipitated into a large excess of $\mathrm{MeOH}$, centrifuged, decanted, and dried overnight under vacuum to afford a white powder.

\section{Recycling $\left[\mathbf{P}_{6,6,6,14}\right]\left[\mathbf{N T f}_{2}\right] \quad$ IL}

A polymerization of TsMAz was performed in $\left[\mathrm{P}_{6,6,6,14}\right]\left[\mathrm{NTf}_{2}\right]$ as described above. At the end of the polymerization, the reaction mixture was precipitated into a large excess of $\mathrm{MeOH}$. The precipitate was collected. The methanol/ $\left[\mathrm{P}_{6,6,6,14}\right]\left[\mathrm{NTf}_{2}\right]$ mixture was then placed under vacuum at $50{ }^{\circ} \mathrm{C}$ for $18 \mathrm{~h}$ to remove $\mathrm{MeOH}$. The resulting $\left[\mathrm{P}_{6,6,6,14}\right]\left[\mathrm{NTf}_{2}\right]$ was used for a subsequent polymerization of TsMAz, again using an identical procedure described above. The ${ }^{1} \mathrm{H}$ spectra of $\mathrm{p}(\mathrm{TsMAz})$ (Figure S12) synthesized in recycled $\left[\mathrm{P}_{6,6,6,14}\right]\left[\mathrm{Tf}_{2} \mathrm{~N}\right]$ ILs is identical to that of $\mathrm{p}(\mathrm{TsMAz})$ formed under the conditions originally reported by Bergman and Toste $\left(\mathrm{DMF}, 50{ }^{\circ} \mathrm{C}\right)^{6}$ and $\mathrm{p}(\mathrm{TsMAz})$ formed from before the recycled $\left[\mathrm{P}_{6,6,6,14}\right]\left[\mathrm{Tf}_{2} \mathrm{~N}\right]$ ILs.

\section{Kinetic Studies.}


All propagation rates were determined from the linear first order kinetic plots, following equations 1 and 2. Equation 1 shows the reduction of monomer concentration, [M], over time. We assume that the number of active chain ends $\left(\mathrm{P}^{-}\right)$remains constant during the polymerization, therefore, $[\mathrm{I}]$ (initiator) $=\left[\mathrm{P}^{-}\right]$. Integration of this equation yields equation 2. Plotting the natural logarithm of monomer consumption with respect to time yields a linear trend, where the slope is $\left(k_{\text {app }}\right)$. The propagation rate $\left(k_{p}\right)$ is determined by dividing $k_{\text {app }}$ by the initial initiator concentration, [I]0. First order kinetics, with respect to monomer, are required for this simplification of equation 2 , and has been reported for similar systems. ${ }^{7}$

$\frac{-d[M]}{d t}=k_{p}\left[P^{-}\right][M]=k_{p}[I][M]$

$\ln _{[M]_{t}}^{[M]_{0}}=k_{\text {app }} t=k_{p}[I]_{0} t$

The propagation rate constants, $k_{p}$, were determined using the monomer and polymer signals for the polymerizations until a conversion of $\geq 60 \%$ was achieved.

$\begin{array}{cclclll}{[\mathrm{M}]_{\mathrm{o}} /[\mathrm{I}]_{\mathrm{o}}} & \text { Temp } & \text { Time } & \begin{array}{c}\text { Isolated } \\ \text { Yields } \%\end{array} & \mathrm{M}_{\mathrm{n}} / \mathrm{KDa} & Ð & \begin{array}{c}\text { Rate const. } \\ \mathrm{Lmol}^{-1} \mathrm{~S}^{-1}\end{array} \\ 20 & 50^{\circ} \mathrm{C} & 12 \mathrm{~h} & 95 & 3.8 & 1.10 & \\ 20+20^{\mathrm{b}} & 50^{\circ} \mathrm{C} & 12 \mathrm{~h}+12 \mathrm{~h} & 95 & 6.5 & 1.18 & \\ 60 & 50^{\circ} \mathrm{C} & 18 \mathrm{~h} & 95 & 8.4 & 1.15 & 16.3 \times 10^{-3} \\ 60 & 60{ }^{\circ} \mathrm{C} & 12 \mathrm{~h} & >95 & 8.22 & 1.11 & 25.4 \times 10^{-3} \\ 60 & 80{ }^{\circ} \mathrm{C} & 4 \mathrm{~h} & >95 & 7.71 & 1.16 & 84.3 \times 10^{-3}\end{array}$

Table S1. Comparison of polymerizations of TsMAz with different temperature and $[\mathrm{M}] /[\mathrm{I}]$ initiator ratios in $\left[\mathrm{P}_{6,6,6,14}\right]\left[\mathrm{Tf}_{2} \mathrm{~N}\right] \mathrm{IL}$. ${ }^{a}$ Living polymerization was studied by adding $20 \mathrm{eq}$ monomer added to a polymerization process $[\mathrm{M}]_{\mathrm{o}} /[\mathrm{I}]_{\mathrm{o}} 20: 1$, b block co-polymer was synthesized by adding 20 eq of pCNTsAz monomer added to a polymerization process $[\mathrm{M}]_{\mathrm{o}}\left[[\mathrm{I}]_{\mathrm{o}} 20: 1\right.$ 


\section{Diffusivity Calculations}

The diffusivities of the monomer units in each of the three solvents were calculated through postprocessing of the simulation trajectories. The mean squared displacements of the centers of mass of each monomer molecule were tracked and then averaged as a function of time. This average mean squared displacement as a function of time is shown in Figure S23.

For each system, a linear regression was performed on the data beyond $20 \mathrm{~ns}$, resulting in a reasonable fit of the data. For a random walk in three dimensions, the averaged mean squared displacement, $\left\langle r^{2}>\right.$, has a linear time-dependence:

$$
<r^{2}>=6 D t
$$

in which $D$ is the diffusion coefficient and $t$ is the elapsed time. The slope of the regression lines can then be used to determine $D$ accordingly. The calculated monomer unit diffusivities in DMF, $\left[\mathrm{C}_{4} \mathrm{dmim}\right]\left[\mathrm{Tf}_{2} \mathrm{~N}\right]$, and $\left[\mathrm{P}_{6,6,6,14}\right]\left[\mathrm{Tf}_{2} \mathrm{~N}\right]$ were determined to be $5.41 \times 10^{-10} \mathrm{~m}^{2} / \mathrm{s}, 1.92 \times 10^{-12} \mathrm{~m}^{2} / \mathrm{s}$, and $1.53 \times 10^{-12} \mathrm{~m}^{2} / \mathrm{s}$, respectively. 


\section{NMR Spectrum}

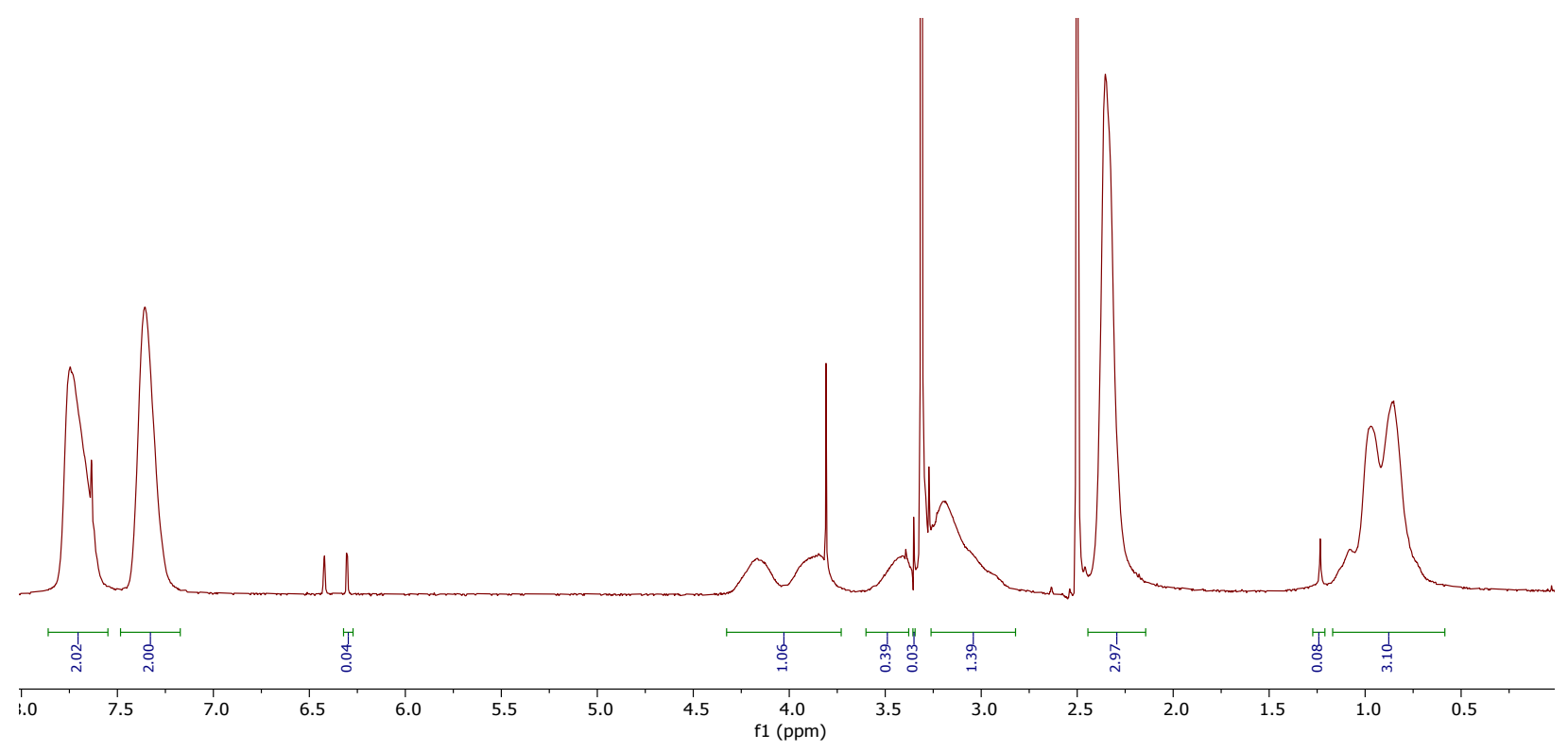

Figure S1. ${ }^{1} \mathrm{H}$ NMR spectrum $\left(\mathrm{DMSO}-\mathrm{d}_{6}\right)$ of $\mathrm{p}(\mathrm{TsMAz})$ synthesized in $\left[\mathrm{C}_{4} \mathrm{dmim}\right]\left[\mathrm{Tf}_{2} \mathrm{~N}\right]$ at $50^{\circ} \mathrm{C}$.

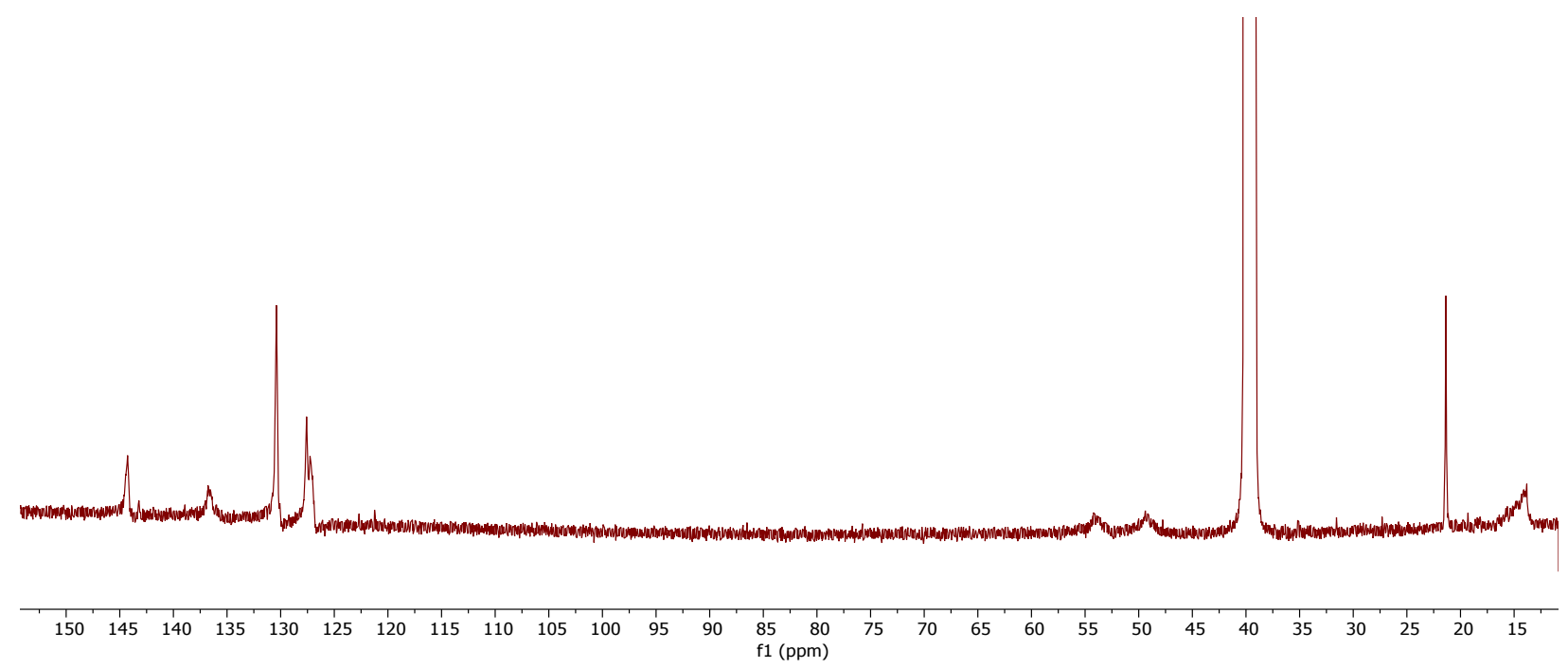

Figure S2. ${ }^{13} \mathrm{C}$ NMR spectrum $\left(\mathrm{DMSO}-\mathrm{d}_{6}\right)$ of $\mathrm{p}(\mathrm{TsMAz})$ synthesized in $\left[\mathrm{C}_{4} \mathrm{dmim}\right]\left[\mathrm{BF}_{4}\right]$ at $50^{\circ} \mathrm{C}$. 


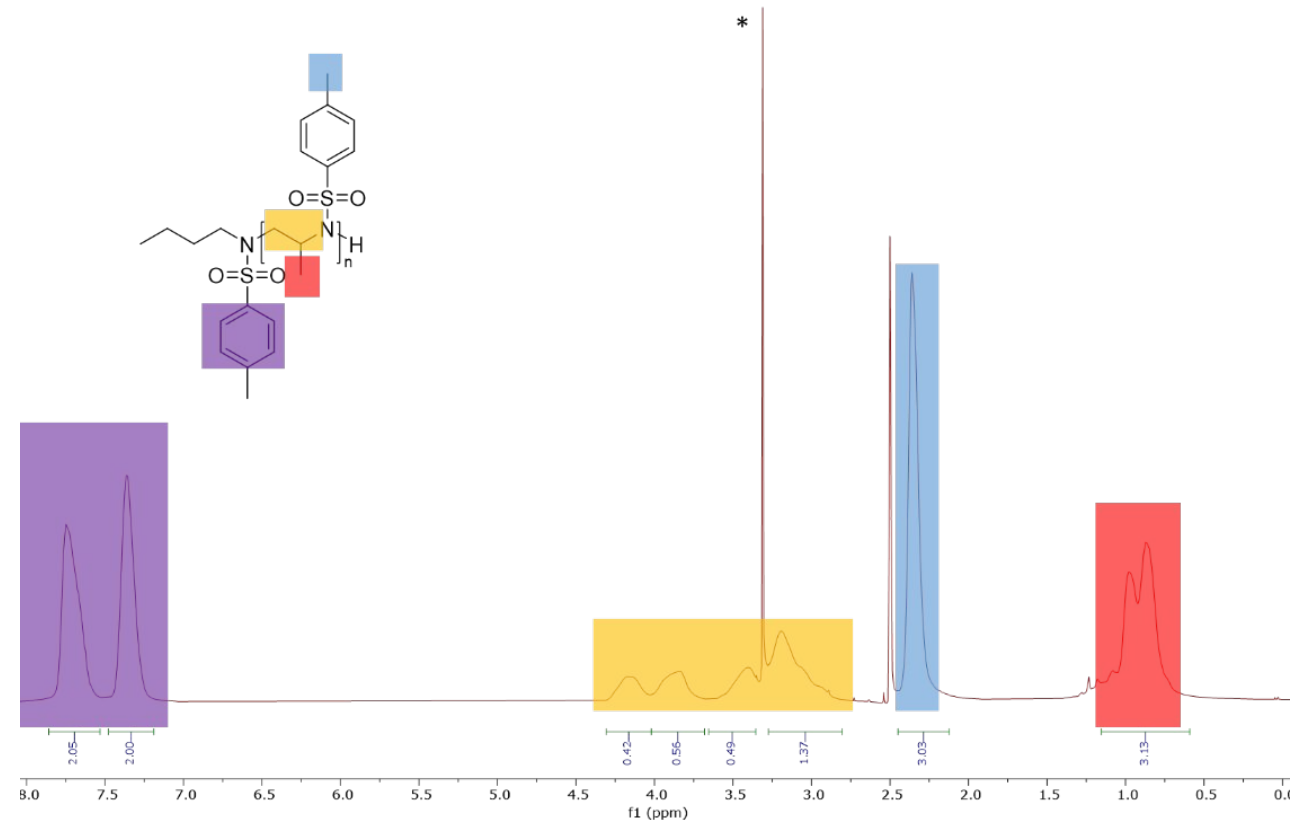

Figure S3. ${ }^{1} \mathrm{H}$ NMR spectrum $\left(\mathrm{DMSO}^{-} \mathrm{d}_{6}\right)$ of $\mathrm{p}(\mathrm{TsMAz})$ synthesized in $\left[\mathrm{P}_{6,6,6,14}\right]\left[\mathrm{Tf}_{2} \mathrm{~N}\right]$ IL at $50^{\circ} \mathrm{C}\left(*=\mathrm{H}_{2} \mathrm{O}\right)$.
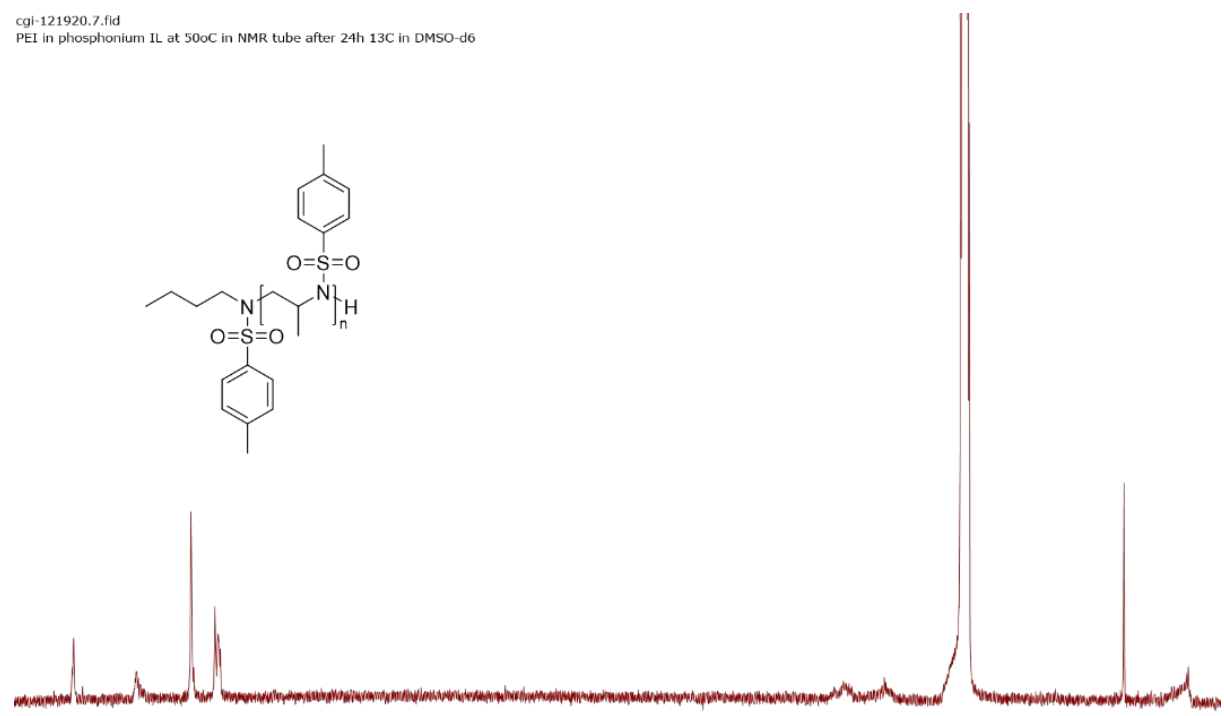

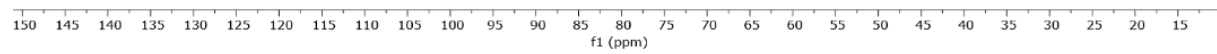

Figure S4. ${ }^{13} \mathrm{C}$ NMR spectrum $\left(\mathrm{DMSO}-\mathrm{d}_{6}\right)$ of $\mathrm{p}(\mathrm{TsMAz})$ synthesized in $\left[\mathrm{P}_{6,6,6,14}\right]\left[\mathrm{Tf}_{2} \mathrm{~N}\right] \mathrm{IL}$. 


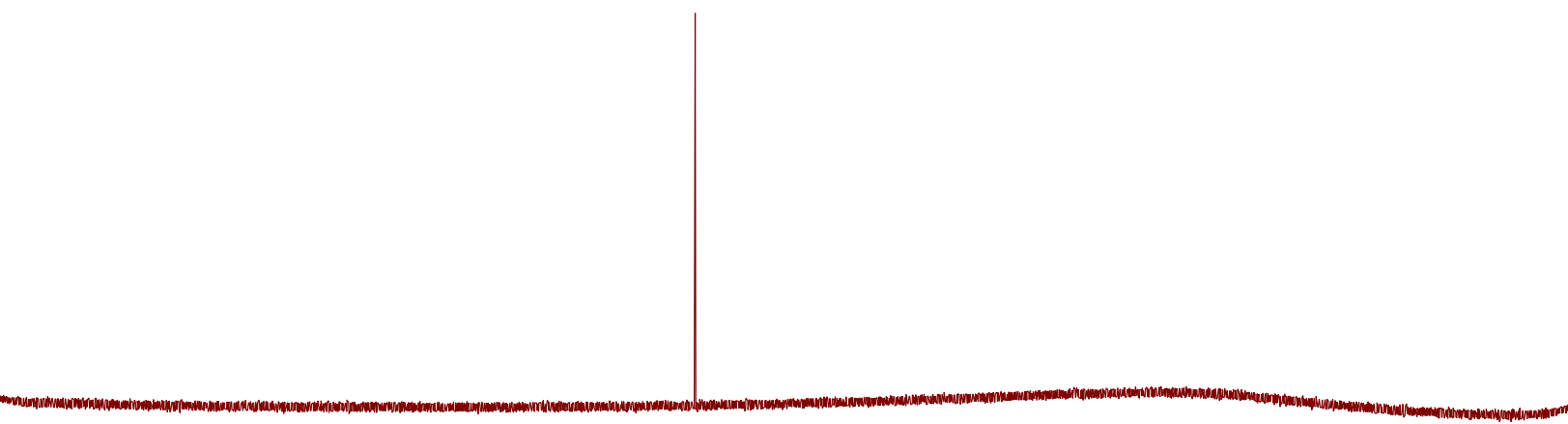

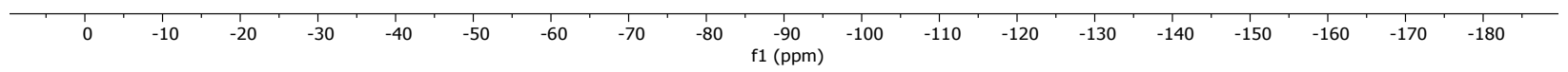

Figure S5. ${ }^{19} \mathrm{~F}$ NMR spectrum (DMSO-d ${ }_{6}$ ) of $\mathrm{p}(\mathrm{TsMAz})$ synthesized in $\left[\mathrm{P}_{6,6,6,14}\right]\left[\mathrm{Tf}_{2} \mathrm{~N}\right]$ IL. The signal is attributed to residual IL trapped in the polymer.

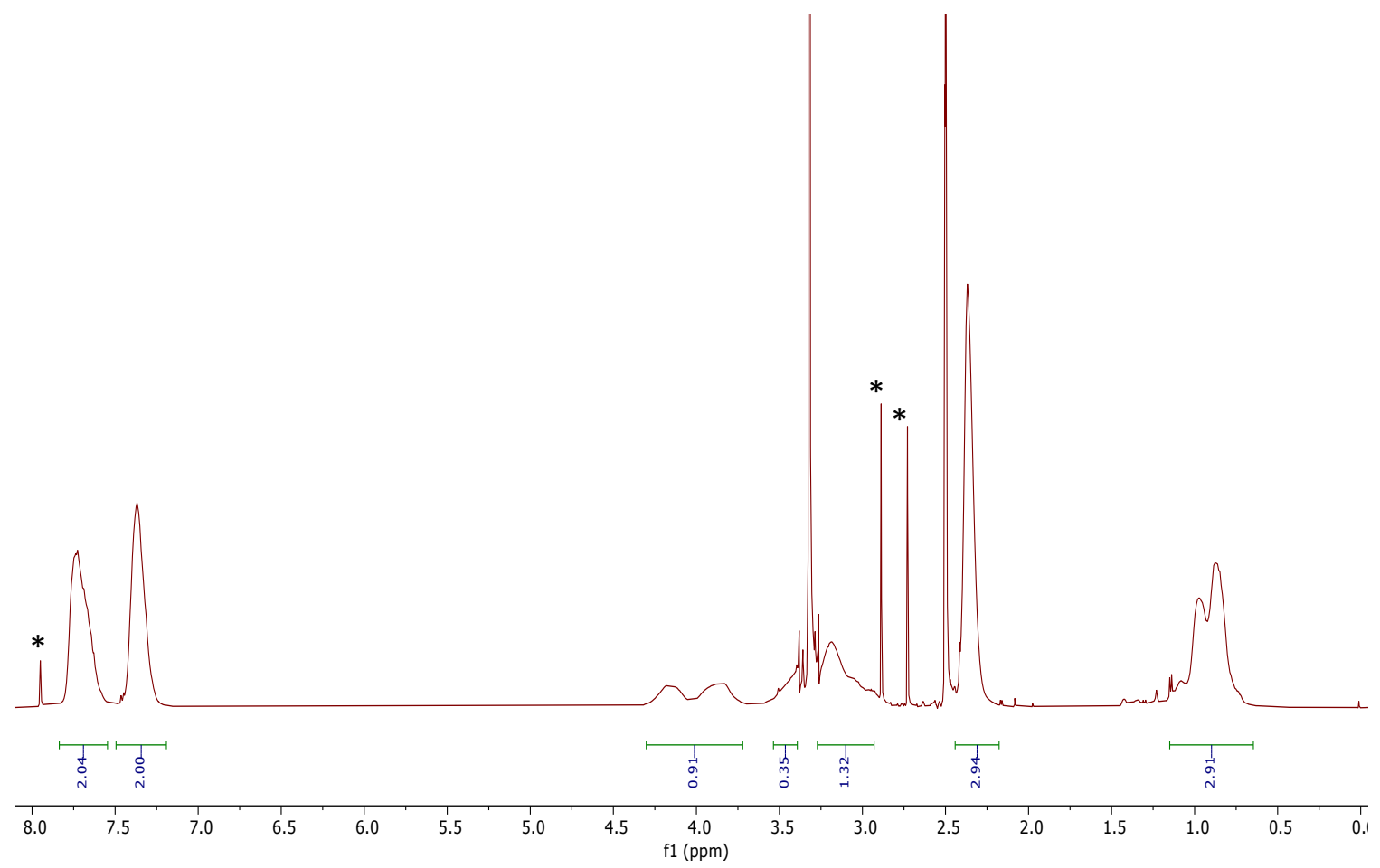

Figure S6. ${ }^{1} \mathrm{H}$ NMR spectrum $\left(\mathrm{DMSO}_{-} \mathrm{d}_{6}\right)$ of $\mathrm{p}(\mathrm{TsMAz})$ synthesized in DMF at $50^{\circ} \mathrm{C} .\left(^{*}=\right.$ $\mathrm{DMF}$ ) 


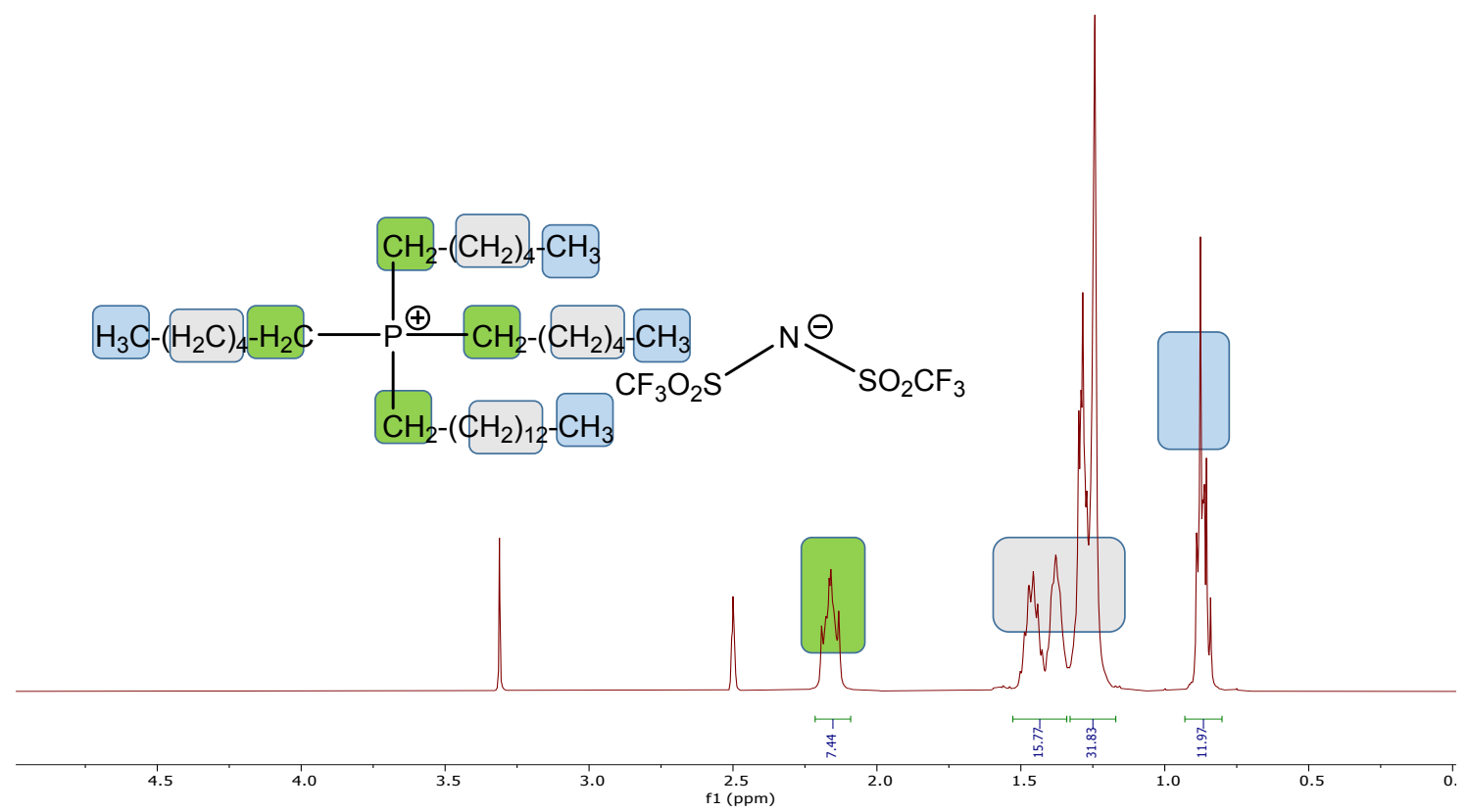

Figure S7. ${ }^{1} \mathrm{H}$ NMR spectrum $\left(\mathrm{DMSO}-\mathrm{d}_{6}\right)$ of $\left[\mathrm{P}_{6,6,6,14}\right]\left[\mathrm{Tf}_{2} \mathrm{~N}\right]$ ionic liquid purchased from Acros.
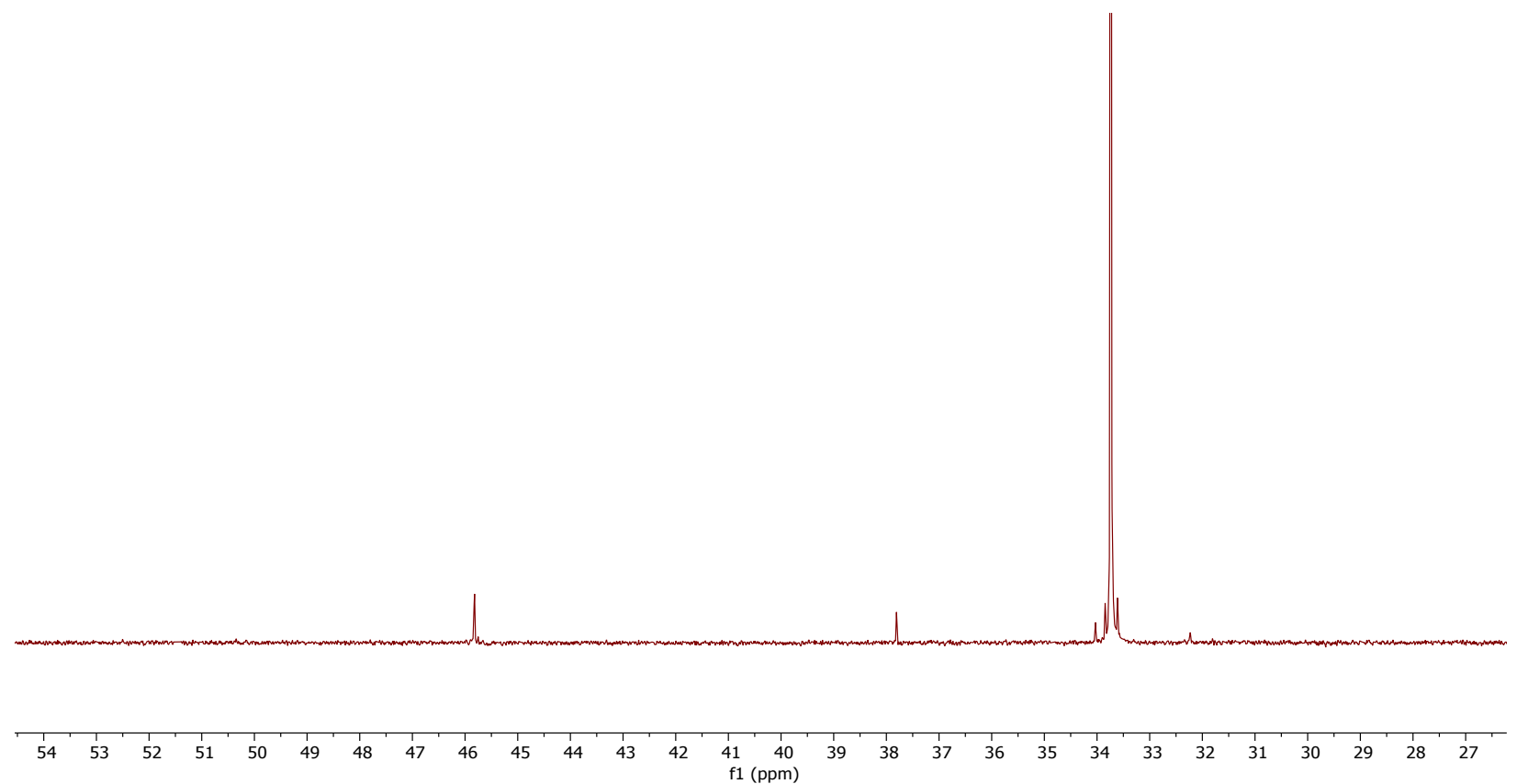

Figure S8. ${ }^{31} \mathrm{P}$ NMR spectrum $\left(\mathrm{DMSO}-\mathrm{d}_{6}\right)$ of $\left[\mathrm{P}_{6,6,6,14}\right]\left[\mathrm{Tf}_{2} \mathrm{~N}\right]$ ionic liquid purchased from Acros. 


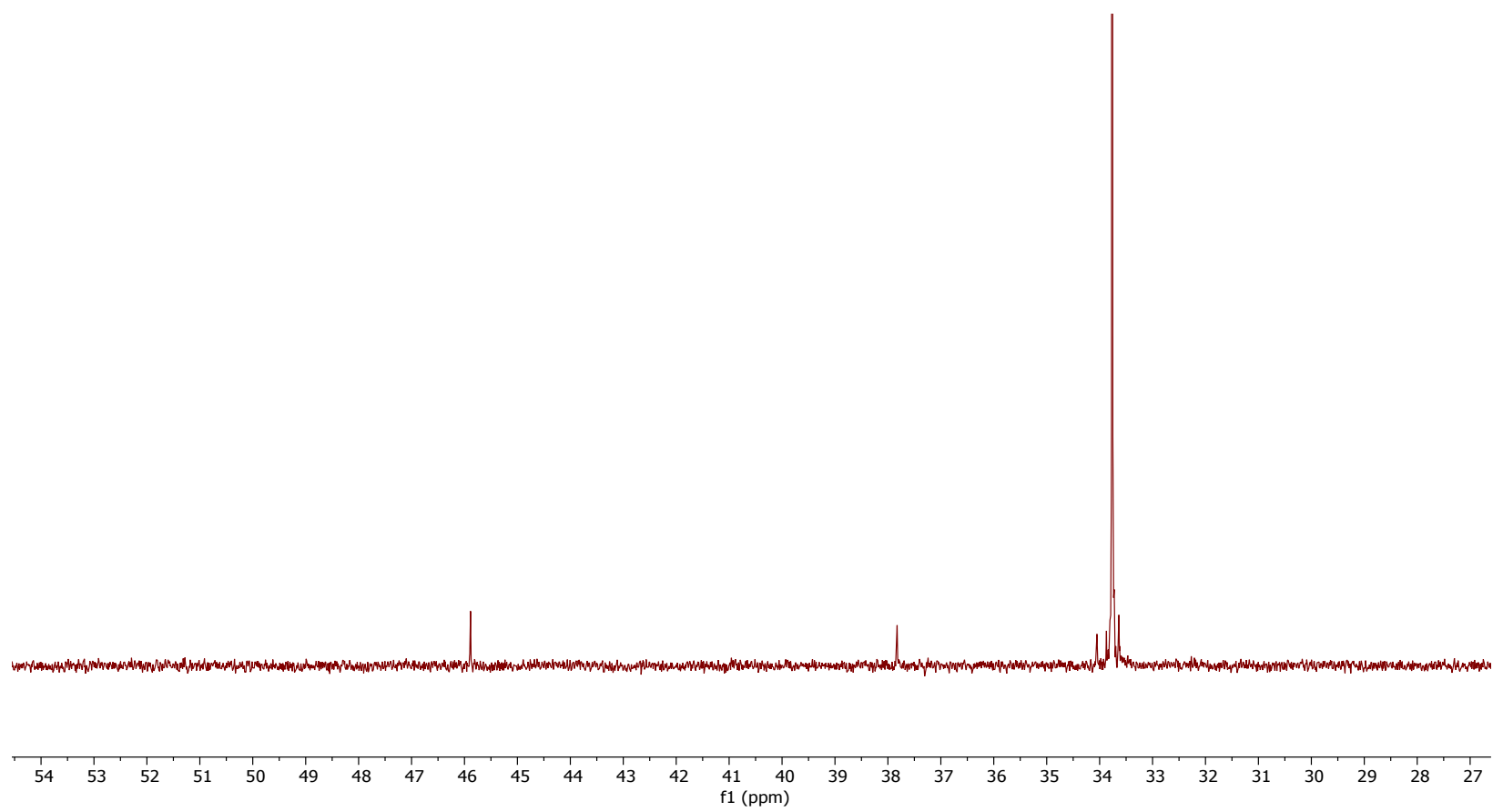

Figure S9. ${ }^{31} \mathrm{P}$ NMR spectrum $\left(\mathrm{DMSO}-\mathrm{d}_{6}\right)$ of $\mathrm{p}(\mathrm{TsMAz})$ polymer and $\left[\mathrm{P}_{6,6,6,14}\right]\left[\mathrm{Tf}_{2} \mathrm{~N}\right]$ ionic liquid after the polymerization of $\mathbf{T s M A z}$ at $50^{\circ} \mathrm{C}$.
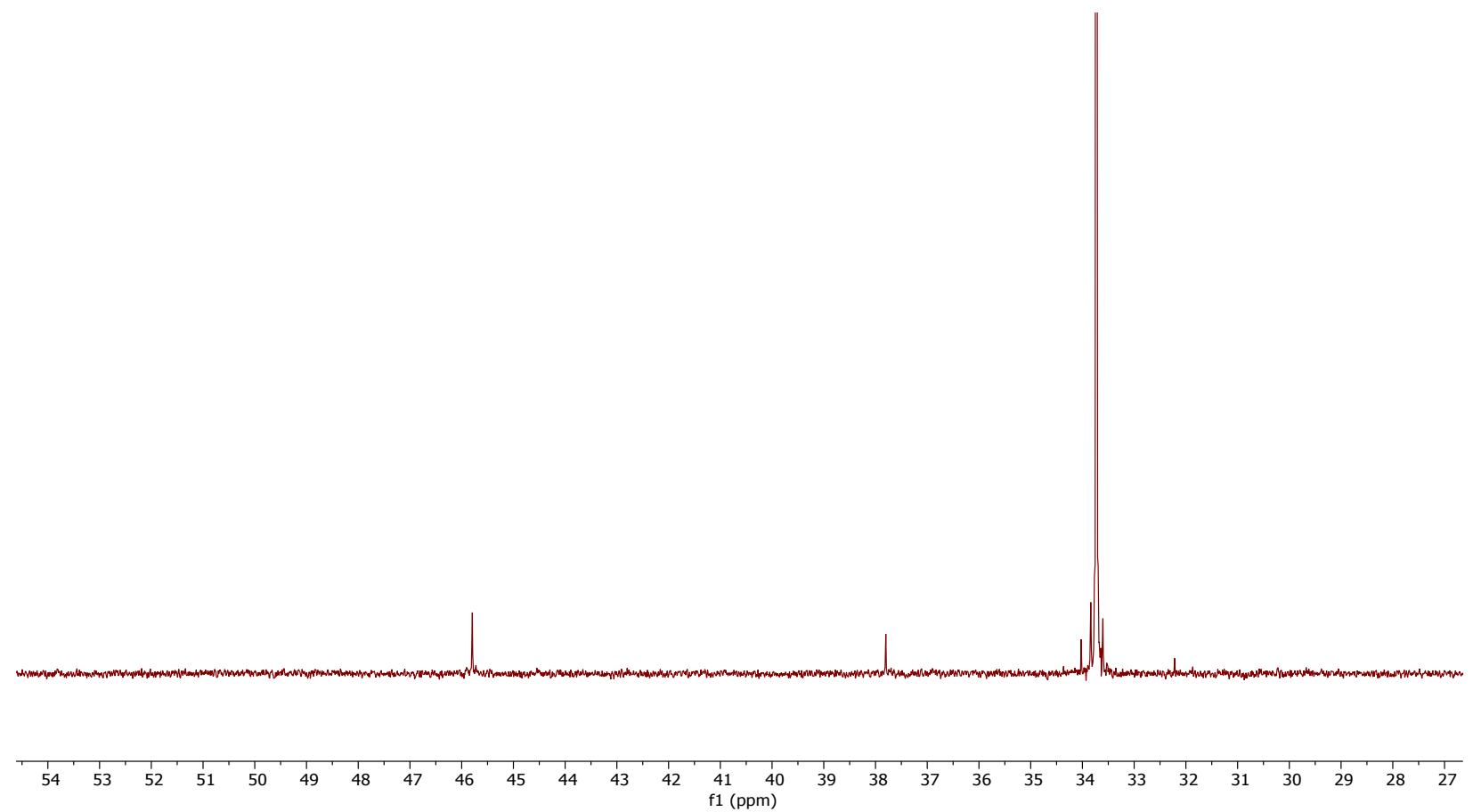

Figure S10. ${ }^{31} \mathrm{P}$ NMR spectrum $\left(\mathrm{DMSO}-\mathrm{d}_{6}\right)$ of $\mathrm{p}(\mathrm{TsMAz})$ and $\left[\mathrm{P}_{6,6,6,14}\right]\left[\mathrm{Tf}_{2} \mathrm{~N}\right]$ ionic liquid after the polymerization of $\mathbf{T s M A z}$ at $80^{\circ} \mathrm{C}$. 
b)

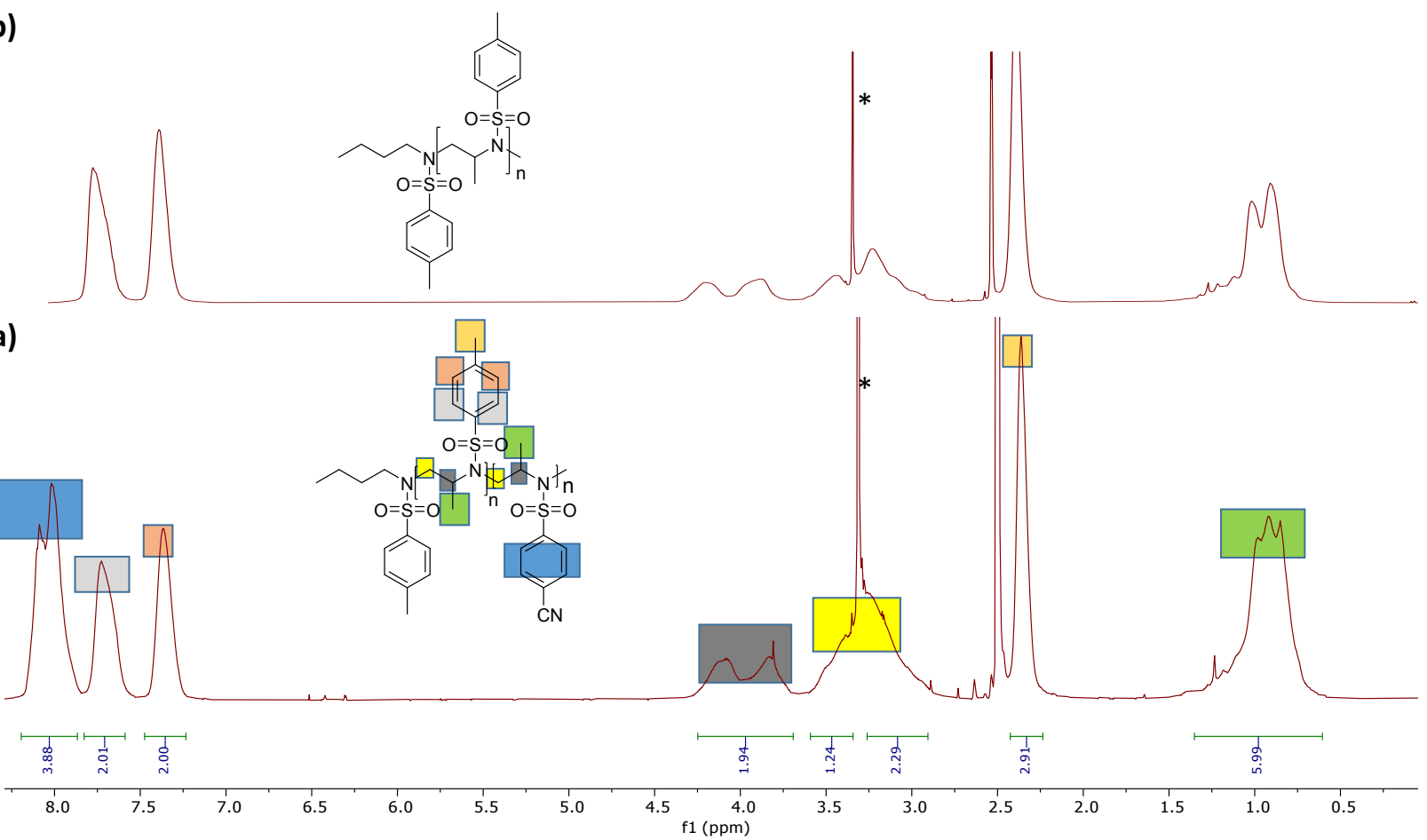

Figure S11. ${ }^{1} \mathrm{H}$ NMR spectrum (DMSO- $\mathrm{d}_{6}$ ) of an aliquot of living $\mathrm{p}(\mathrm{TsMAz})$, quenched in $\mathrm{MeOH}$ and dried. b) ${ }^{1} \mathrm{H}$ NMR spectrum (DMSO-d $\mathrm{d}_{6}$ ) of the block copolymer $\mathrm{p}$ (TsMAz)- $b$-p(pCNMAz). * $\mathrm{H}_{2} \mathrm{O}$

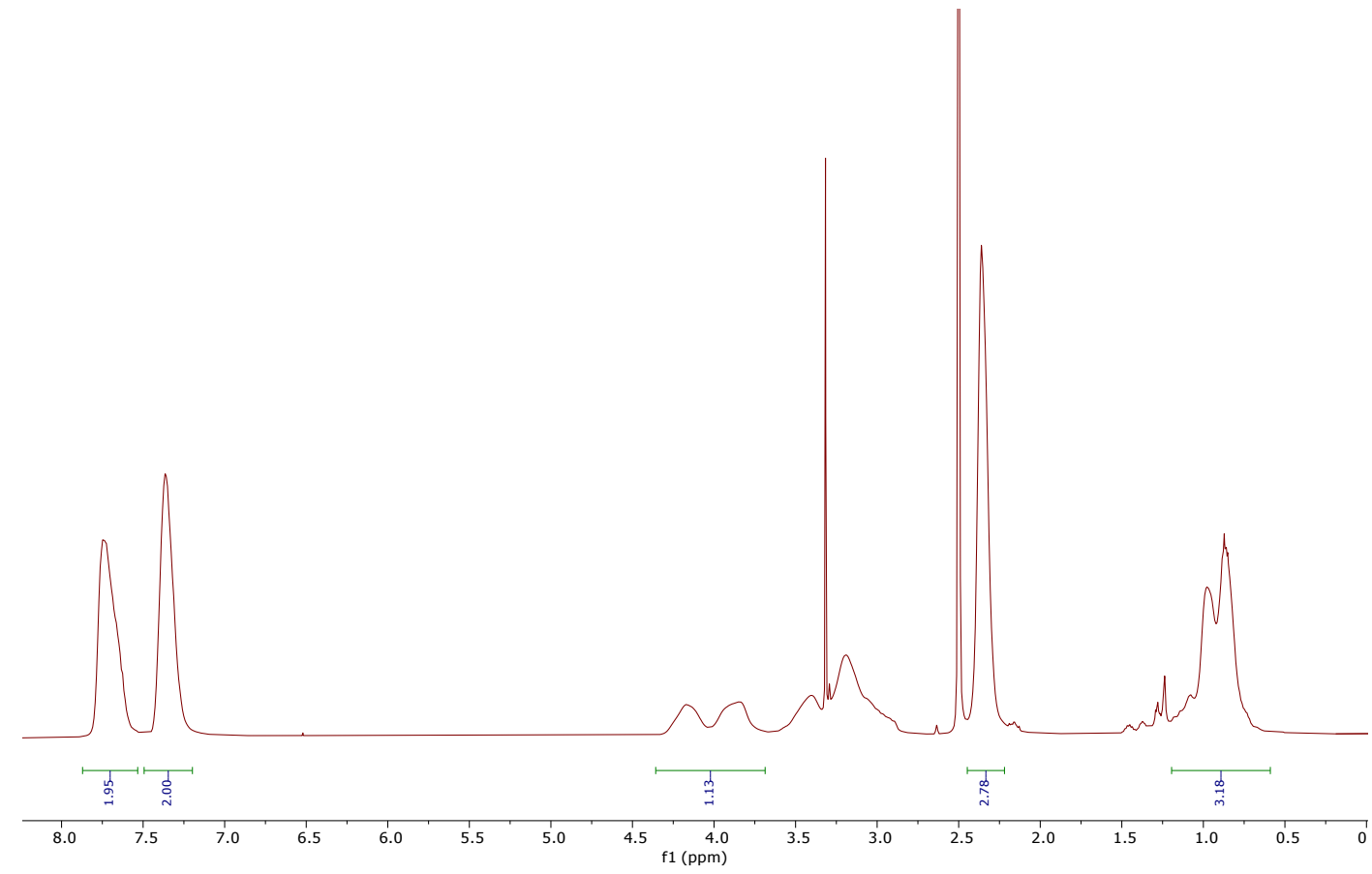

Figure S12: ${ }^{1} \mathrm{H}$ NMR spectrum $\left(\mathrm{DMSO}-\mathrm{d}_{6}\right)$ of $\mathrm{p}(\mathrm{TsMAz})$ synthesized in recycled $\left[\mathrm{P}_{6,6,6,14}\right]\left[\mathrm{Tf}_{2} \mathrm{~N}\right]$ IL at $50^{\circ} \mathrm{C}$ 
Kinetic Plots.

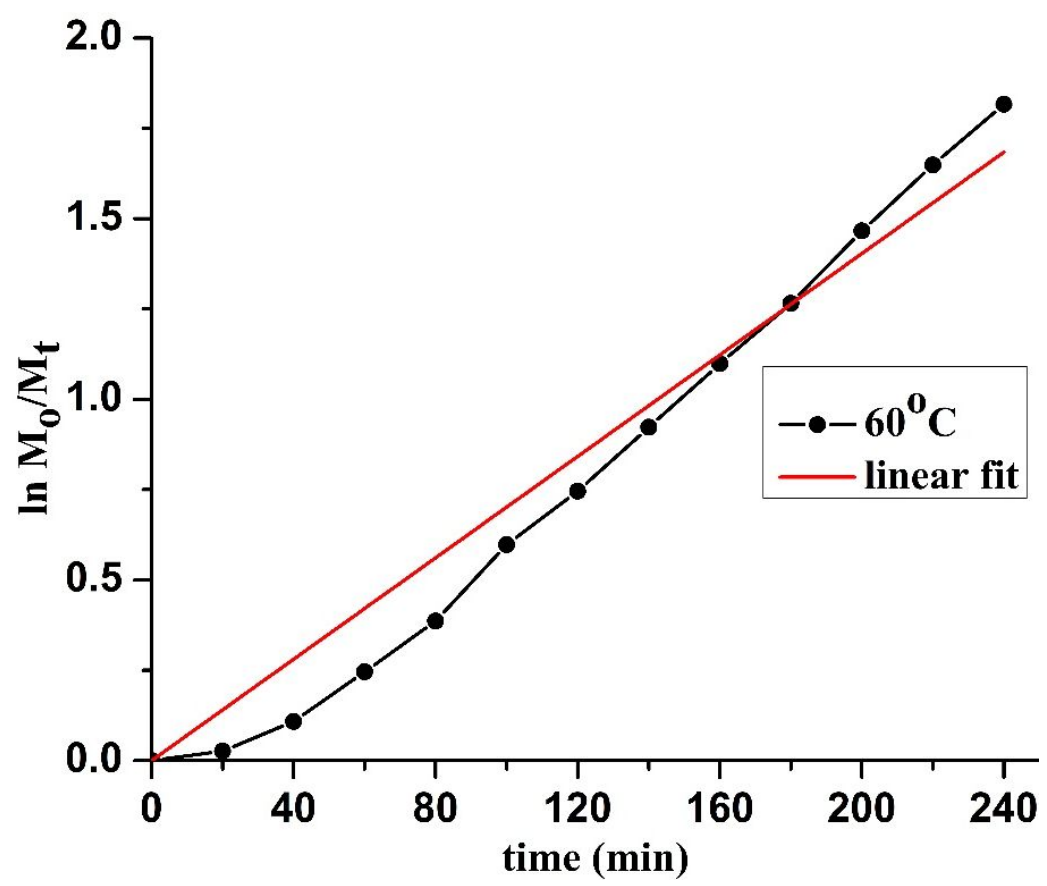

Figure S13. Kinetic plot for the polymerization of TsMAz in $\left[\mathrm{C}_{4} \mathrm{dmim}\right]\left[\mathrm{Tf} f_{2} \mathrm{~N}\right]$ IL at $60^{\circ} \mathrm{C}$. The consumption of TsMAz was monitored by ${ }^{1} \mathrm{H}$ NMR spectroscopy.

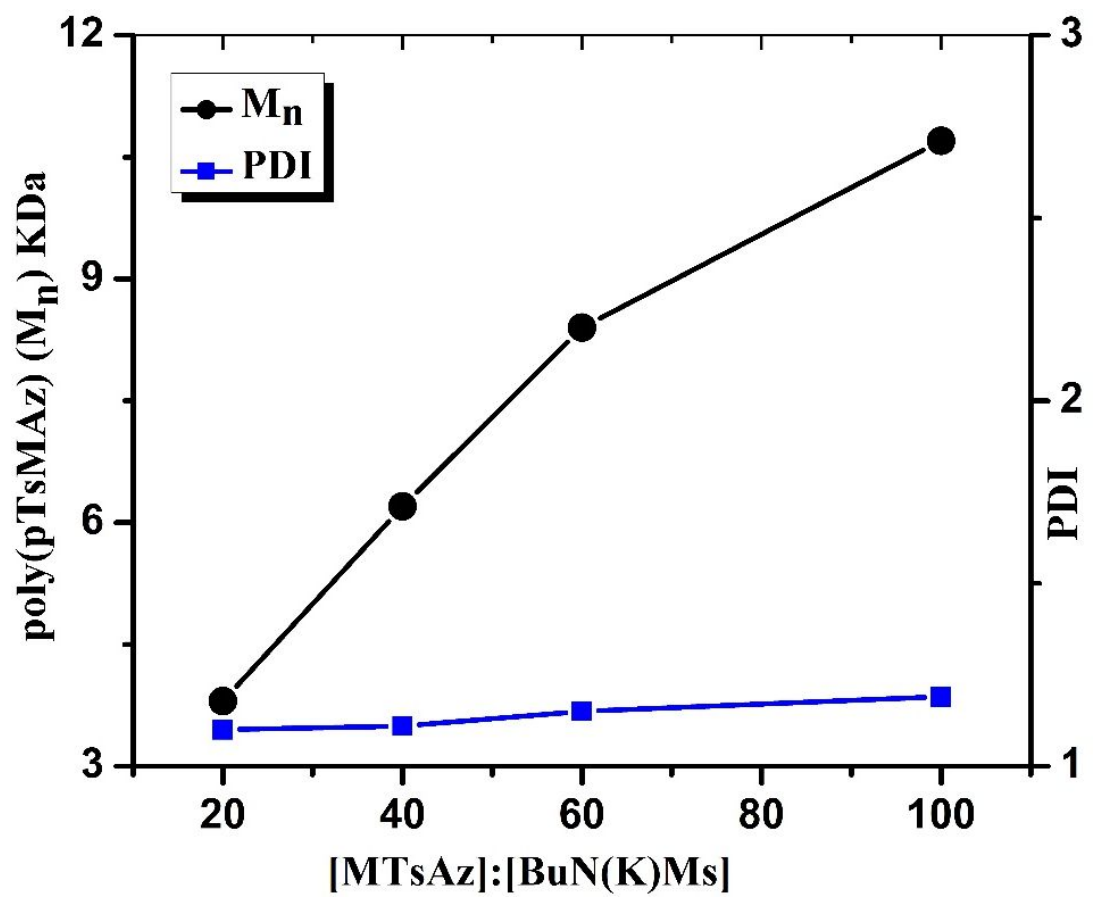

Figure S14. The $M_{n}$ (versus a PS standard) and $Đ$ were plotted with different variant of monomer initiator ratios. 


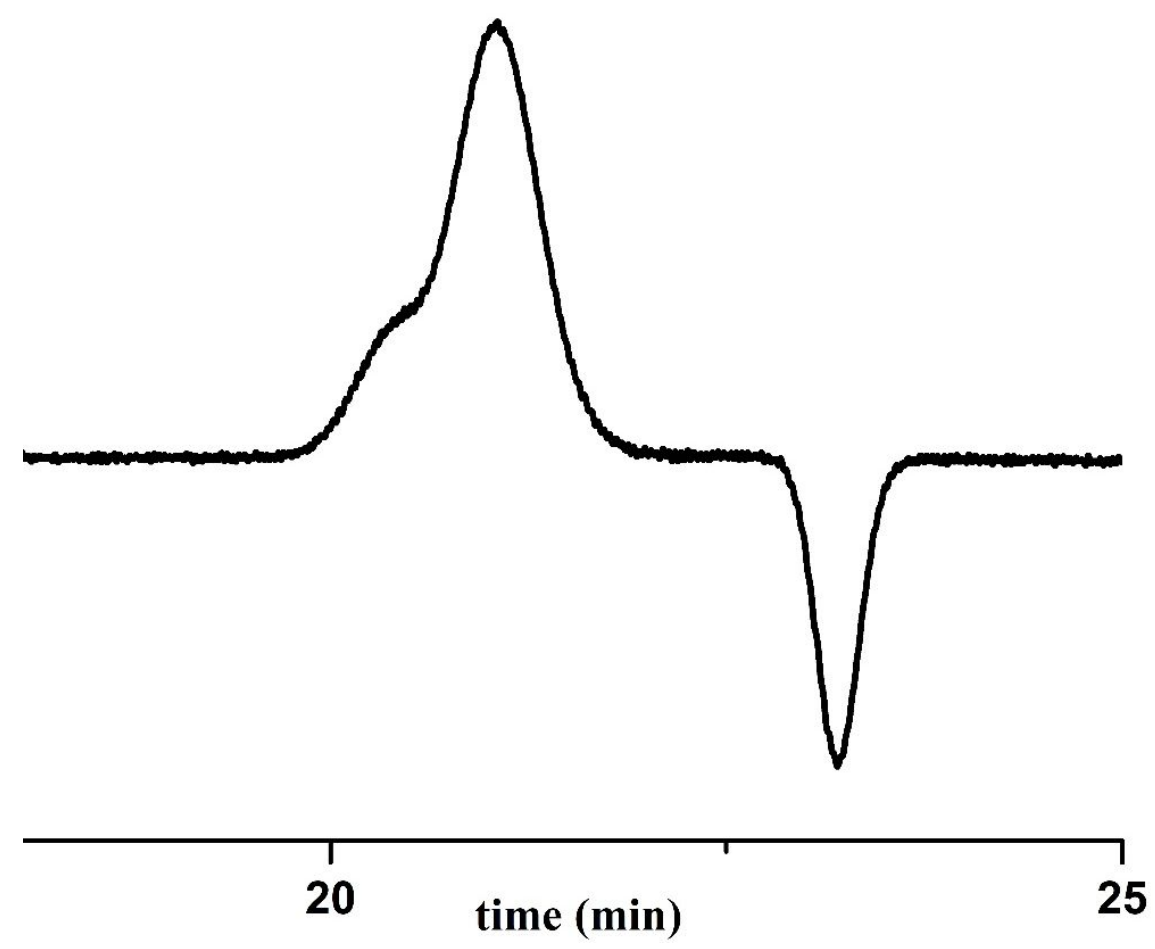

Figure S15. SEC analysis (DMF, $1 \mathrm{~mL} / \mathrm{min})$ of $\mathrm{p}(\mathrm{TsMAz})$ synthesized in $\left[\mathrm{C}_{4} \mathrm{dmim}\right]\left[\mathrm{Tf}_{2} \mathrm{~N}\right]$. The $[\mathrm{M}]:[\mathrm{I}]$ for the synthesis of this polymer sample was 60:1.

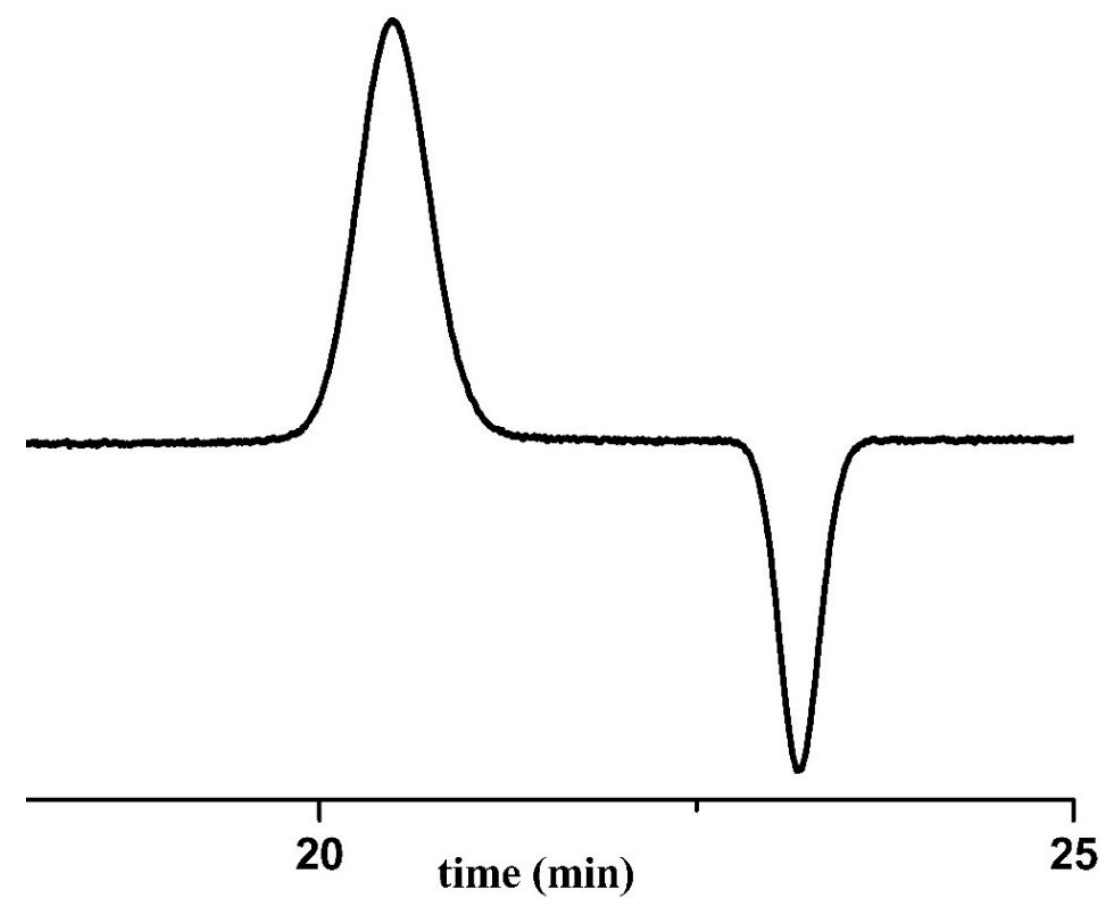

Figure S16. SEC analysis (DMF, $1 \mathrm{~mL} / \mathrm{min})$ of $\mathrm{p}(\mathrm{TsMAz})$ synthesized in $\left[\mathrm{P}_{6,6,6,14}\right]\left[\mathrm{Tf}_{2} \mathrm{~N}\right]$. The $[\mathrm{M}]:[\mathrm{I}]$ for the synthesis of this polymer sample was $60: 1$. 

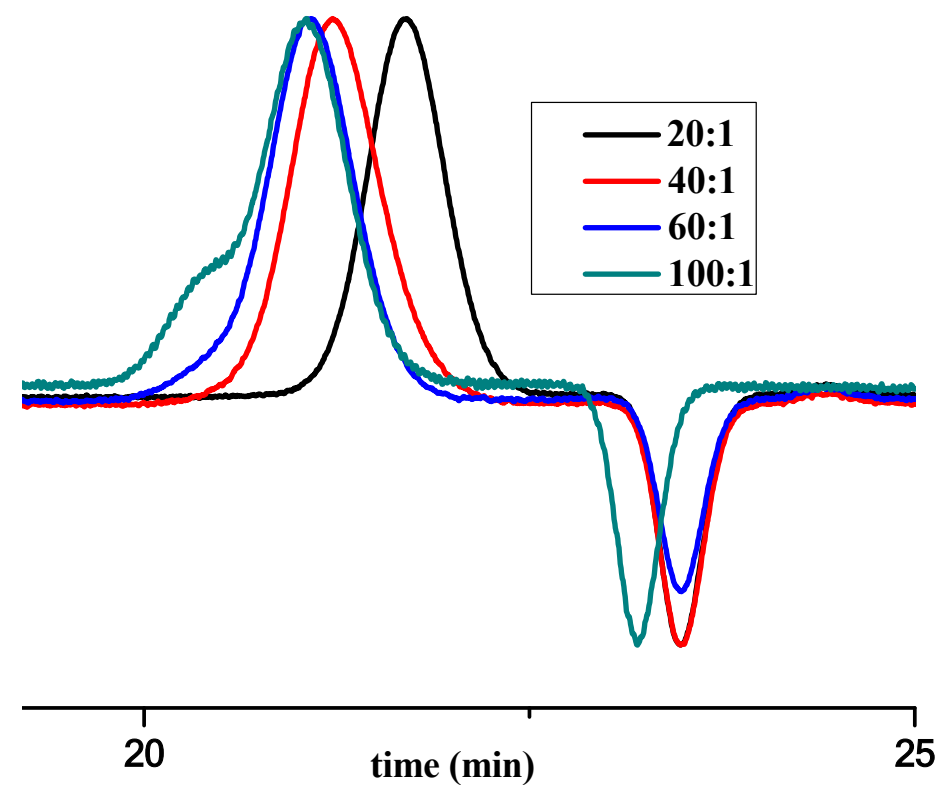

Figure S17. SEC analysis (DMF, $1 \mathrm{~mL} / \mathrm{min})$ of $\mathrm{p}(\mathrm{TsMAz})$ synthesized in $\left[\mathrm{P}_{6,6,6,14}\right]\left[\mathrm{Tf}_{2} \mathrm{~N}\right]$ at different $[\mathrm{M}]:[\mathrm{I}]$ ratio.

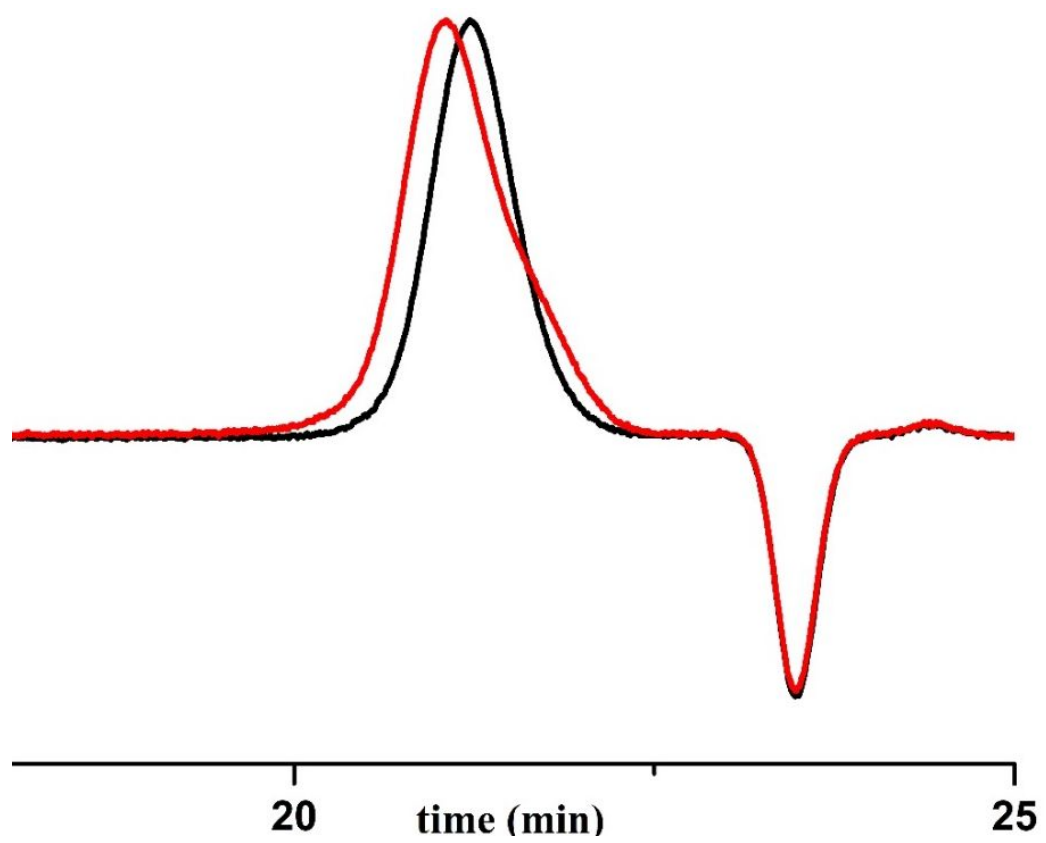

Figure S18. Black trace- SEC analysis (DMF, $1 \mathrm{~mL} / \mathrm{min}$ ) of an aliquot of living $\mathrm{p}(\mathrm{TsMAz})$ synthesized in $\left[\mathrm{P}_{6,6,6,14}\right]\left[\mathrm{Tf}_{2} \mathrm{~N}\right]$. Red trace- SEC analysis (DMF, $\left.1 \mathrm{~mL} / \mathrm{min}\right)$ of $\mathrm{p}(\mathrm{TsMAz})-b$ $\mathrm{p}(\mathrm{pCNMAz})$ synthesized by the addition of pCNMAz to living $\mathrm{p}(\mathrm{TsMAz})$. 


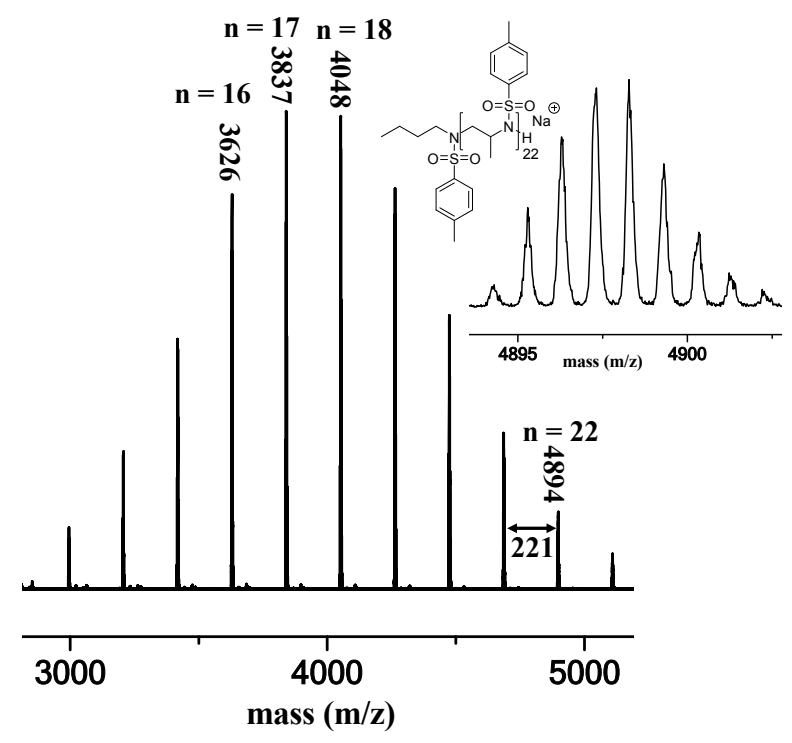

Figure S19. MALDI spectrum of $p(T s M A z)$ synthesized in $\left[\mathrm{C}_{4} \mathrm{dmim}\right]\left[\mathrm{Tf}_{2} \mathrm{~N}\right]$. The $[\mathrm{M}]:[\mathrm{I}]$ for the synthesis of this polymer sample was 25:1. Inset figure is the isotope pattern of $n=22$ repeating unit. This is the same spectra as found in Figure 1A.

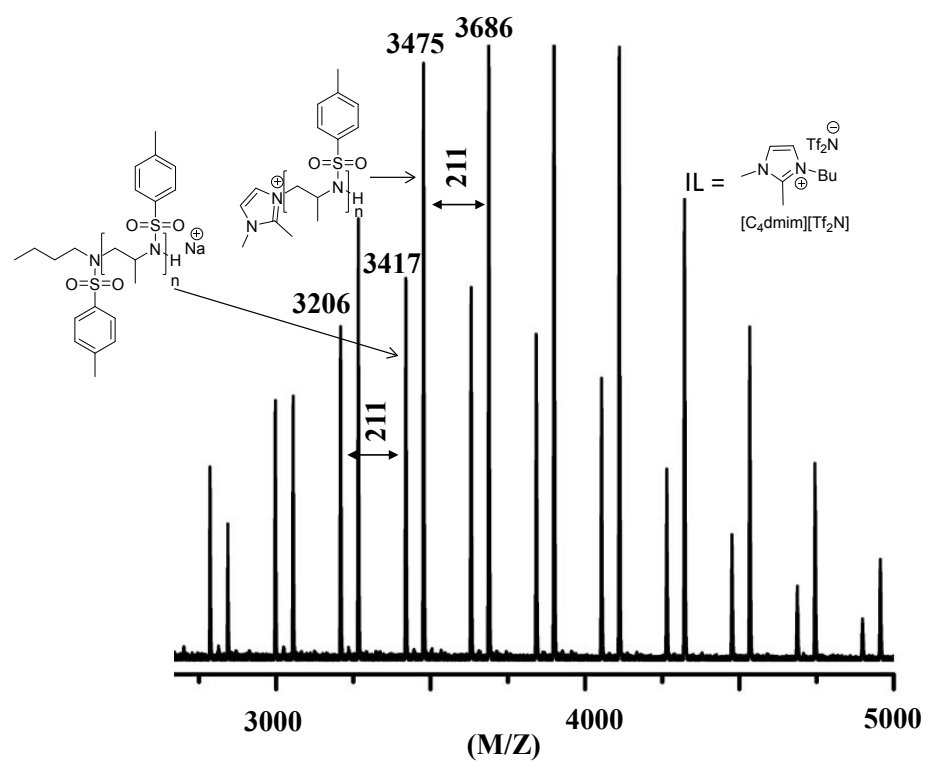

Figure S20. MALDI-TOF mass spectrum of $p(T s M A z)$ synthesized in $\left[\mathrm{C}_{4} \mathrm{dmim}\right]\left[\mathrm{Tf}_{2} \mathrm{~N}\right] \mathrm{IL}$. The $[\mathrm{M}]:[\mathrm{I}]$ for the synthesis of this polymer sample was 60:1. Two polymer series are apparent in the spectrum. One is attributed to chains initiated from $\mathbf{B u}(\mathbf{N}) \mathbf{K T s}$, while the other series is due to initiation from 1,2-dimethylimidazole. This spectra is the same spectra as that shown in Figure $1 B$. 


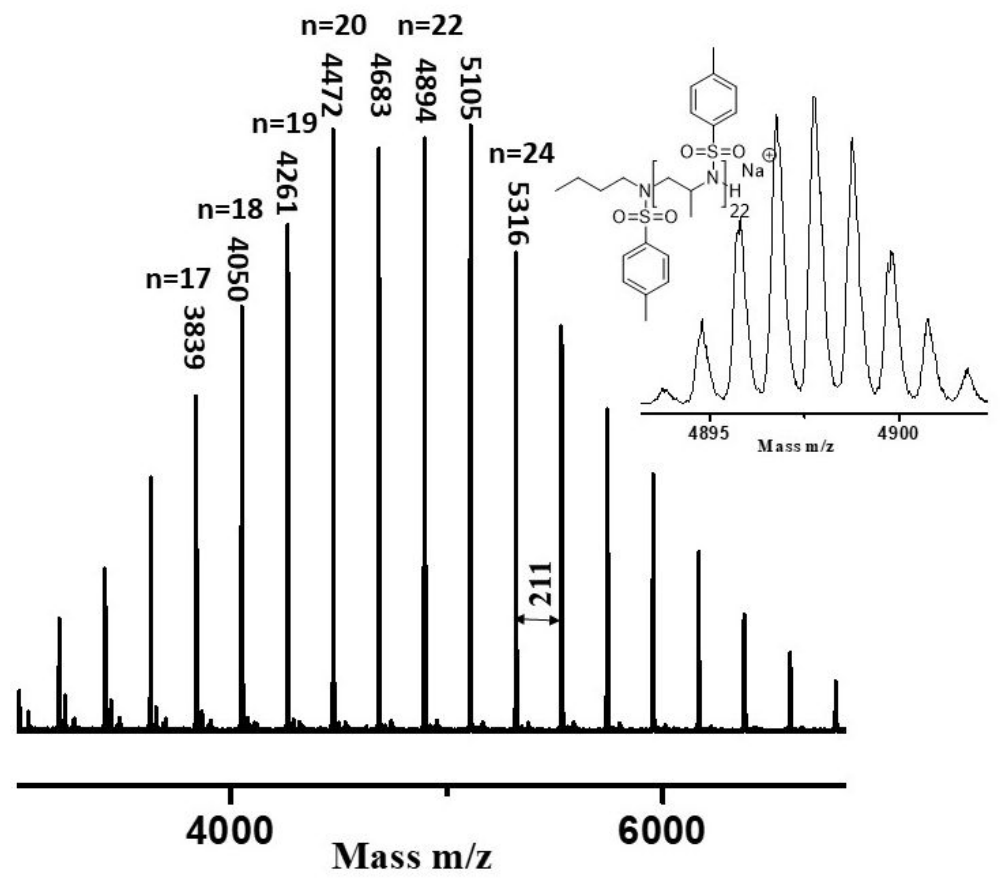

Figure S21. MALDI spectrum of $p(T s M A z)$ synthesized in $\left[\mathrm{P}_{6,6,6,14}\right]\left[\mathrm{NTf}_{2}\right]$. The $[\mathrm{M}]:[\mathrm{I}]$ for the synthesis of this polymer sample was 60:1. Inset figure is the isotope pattern of $n=22$ repeating unit.

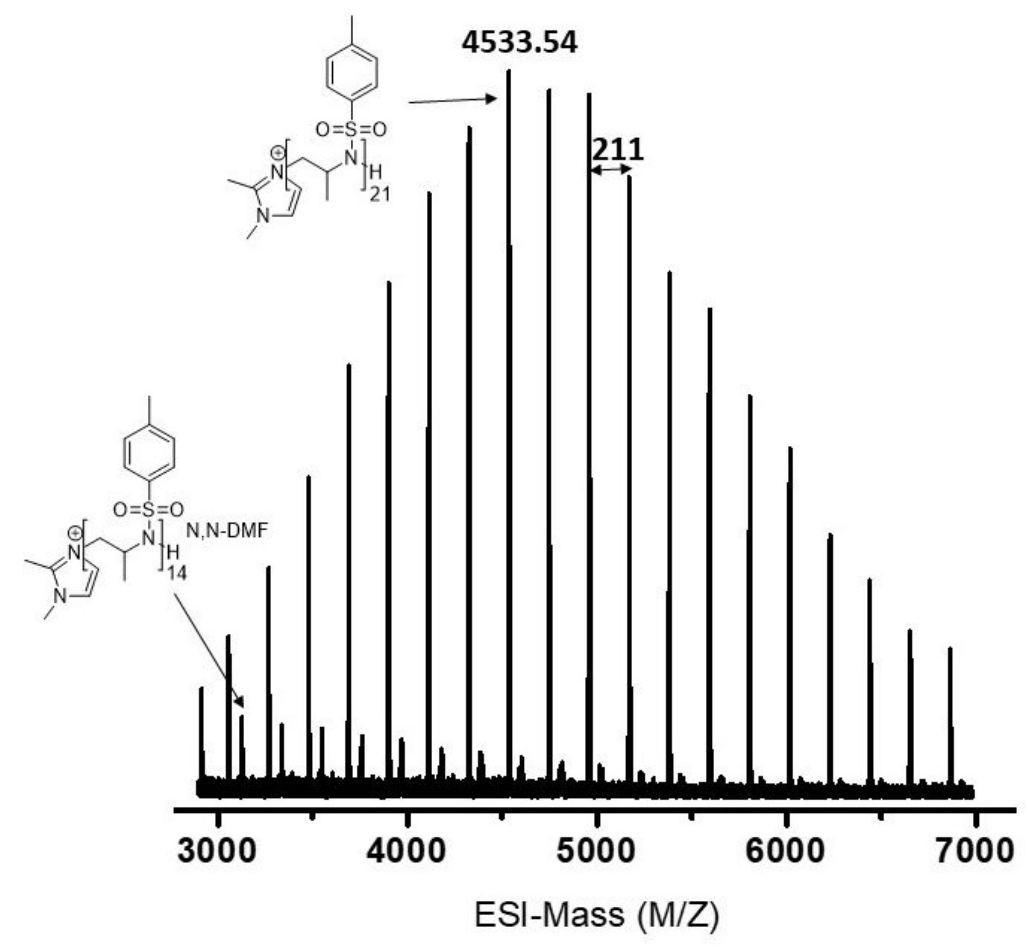

Figure S22. MALDI spectrum of $\mathrm{p}(\mathrm{TsMAz})$ synthesized in DMF with 1,2 dimethyl imidazole initiator. 


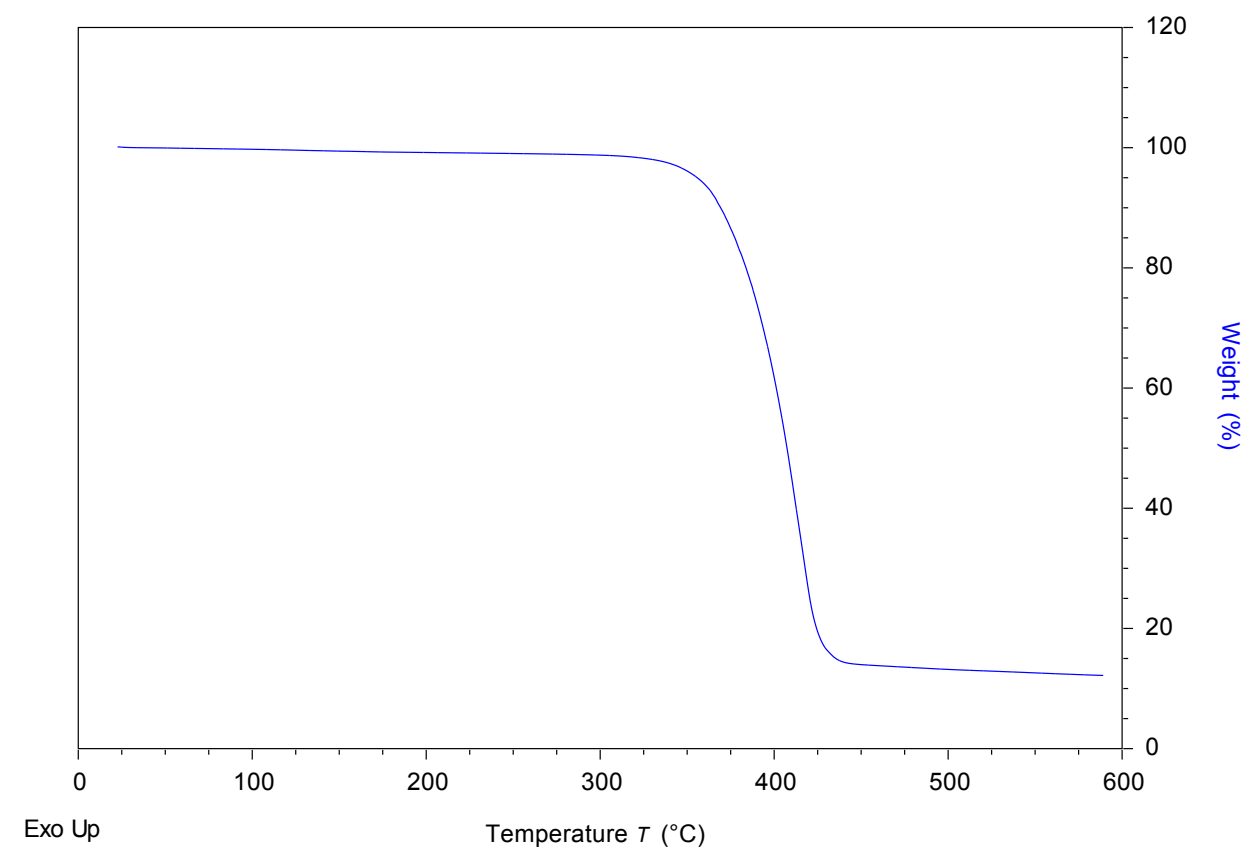

Figure S23. TGA analysis of $\mathrm{p}(\mathrm{TsMAz})$ synthesized in $\left[\mathrm{P}_{6,6,6,14}\right]\left[\mathrm{Tf}_{2} \mathrm{~N}\right]$ IL. The sample was heated at $10{ }^{\circ} \mathrm{C} / \mathrm{min}$ from $40{ }^{\circ} \mathrm{C}$ to $600{ }^{\circ} \mathrm{C}$.

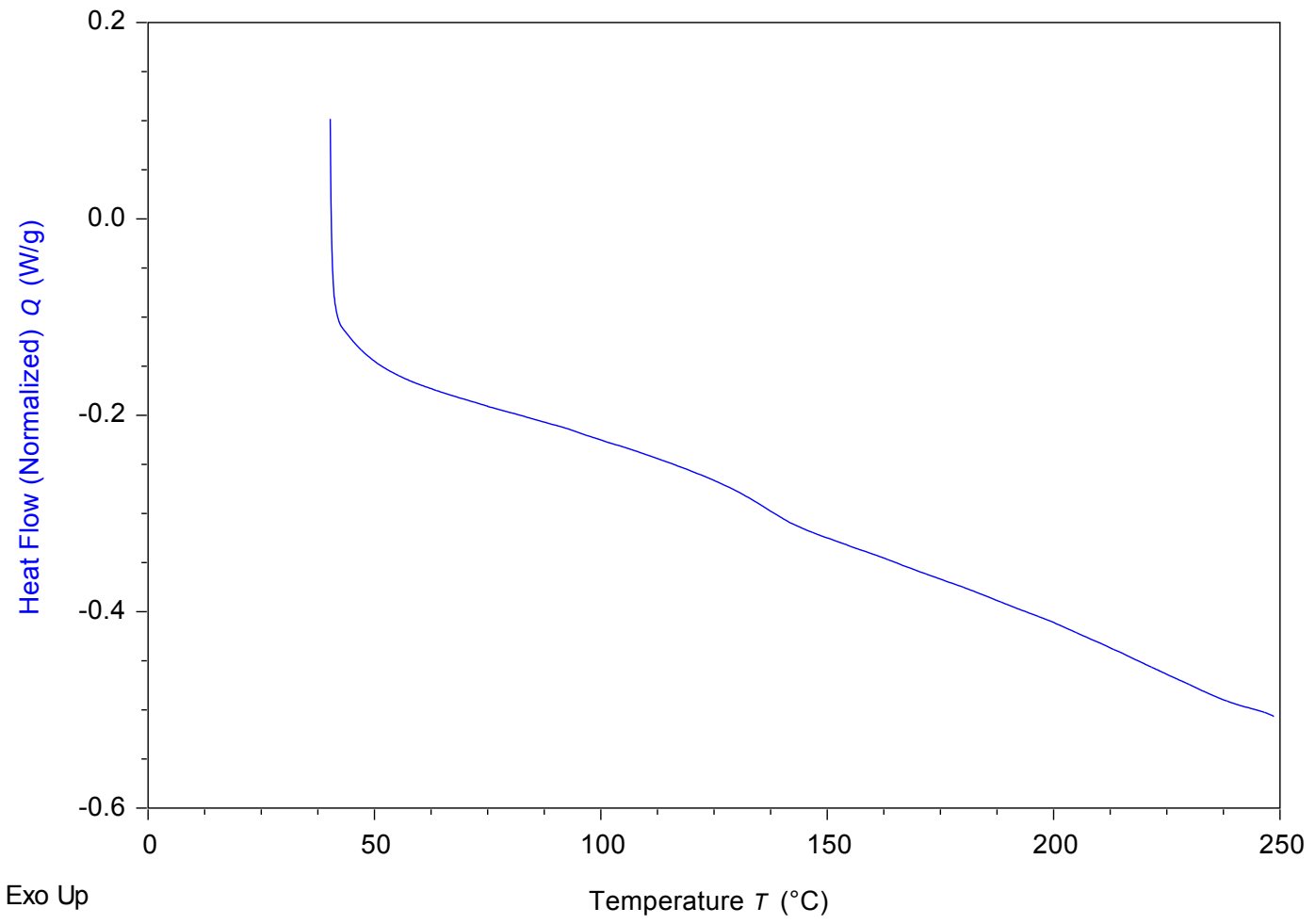

Figure S24. DSC analysis of $\mathrm{p}(\mathrm{TsMAz})$ synthesized in $\left[\mathrm{P}_{6,6,6,14}\right]\left[\mathrm{Tf}_{2} \mathrm{~N}\right]$ IL. The second heating cycle of $40-250{ }^{\circ} \mathrm{C}$ at $10^{\circ} \mathrm{C} / \mathrm{min}$ is shown. 

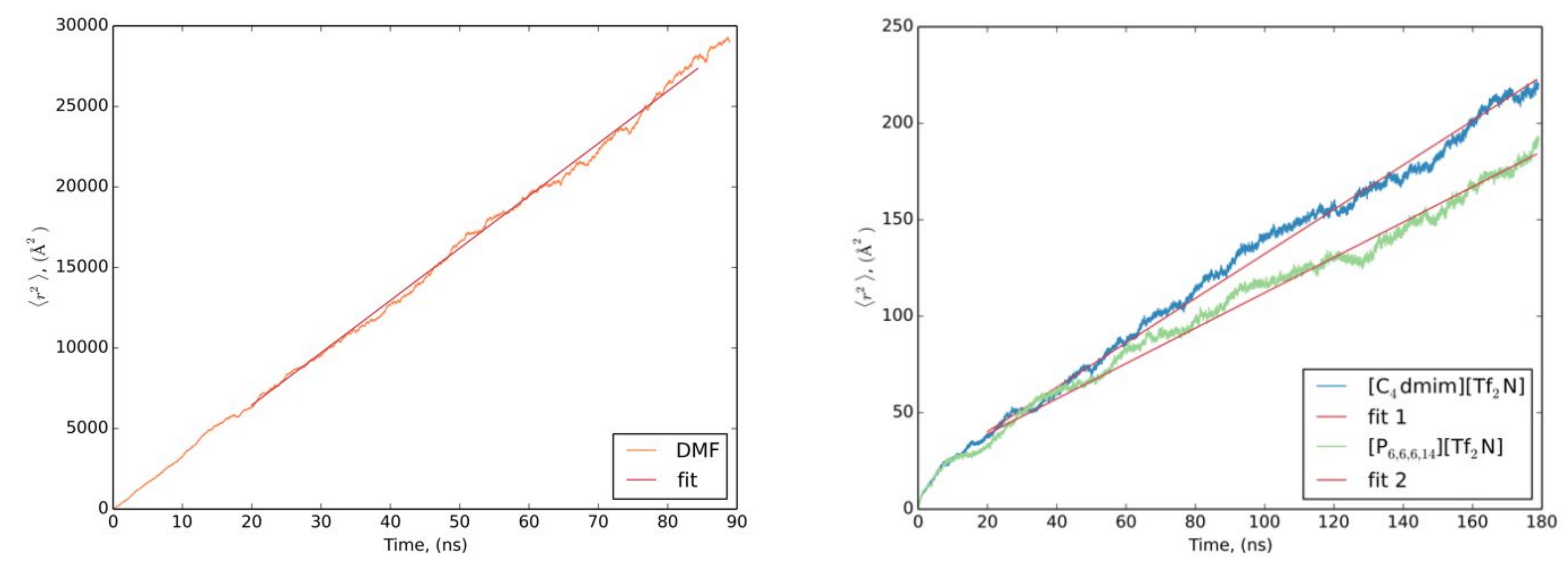

Figure S25: Averaged mean squared displacements of the monomer units (TsMAz) as a function of time for (left) the DMF simulation and (right) the $\left[\mathrm{C}_{4} \mathrm{dmim}\right]\left[\mathrm{Tf}_{2} \mathrm{~N}\right]$ and $\left[\mathrm{P}_{6,6,6,14}\right]\left[\mathrm{Tf}_{2} \mathrm{~N}\right]$ simulations. Red lines show the corresponding linear fits of the data that were used in the calculation of the diffusivities.

References:

(1) Wang, J. W., R.M.; Caldwell, J.W.; Kollman, P.A.; Case, D.A. Development and Testing of a General Amber Force Field. J. Comput. Chem. 2004, 25, 1157-1174.

(2) Gaussian 16, R. C., Frisch, M. J.; Trucks, G. W.; Schlegel, H. B.; Scuseria, G. E.; Robb, M. A.; Cheeseman, J. R.; Scalmani, G.; Barone, V.; Petersson, G. A.; Nakatsuji, H.; Li, X.; Caricato, M.; Marenich, A. V.; Bloino, J.; Janesko, B. G.; Gomperts, R.; Mennucci, B.; Hratchian, H. P.; Ortiz, J. V.; Izmaylov, A. F.; Sonnenberg, J. L.; Williams-Young, D.; Ding, F.; Lipparini, F.; Egidi, F.; Goings, J.; Peng, B.; Petrone, A.; Henderson, T.; Ranasinghe, D.; Zakrzewski, V. G.; Gao, J.; Rega, N.; Zheng, G.; Liang, W.; Hada, M.; Ehara, M.; Toyota, K.; Fukuda, R.; Hasegawa, J.; Ishida, M.; Nakajima, T.; Honda, Y.; Kitao, O.; Nakai, H.; Vreven, T.; Throssell, K.; Montgomery, J. A., Jr.; Peralta, J. E.; Ogliaro, F.; Bearpark, M. J.; Heyd, J. J.; Brothers, E. N.; Kudin, K. N.; Staroverov, V. N.; Keith, T. A.; Kobayashi, R.; Normand, J.; Raghavachari, K.; Rendell, A. P.; Burant, J. C.; Iyengar, S. S.; Tomasi, J.; Cossi, M.; Millam, J. M.; Klene, M.; Adamo, C.; Cammi, R.; Ochterski, J. W.; Martin, R. L.; Morokuma, K.; Farkas, O.; Foresman, J. B.; Fox, D. J. Gaussian, Inc., Wallingford CT, 2016. Gaussian. 
(3) Martinez, L.; Andrade, R.; Birgin, E. G.; Martinez, J. M. PACKMOL: a package for building initial configurations for molecular dynamics simulations. J. Comput. Chem. 2009, $30,2157-2164$.

(4) Laha, J. K.; Sharma, S.; Dayal, N. Palladium-Catalyzed Regio- and Chemoselective Reactions of 2-Bromobenzyl Bromides: Expanding the Scope for the Synthesis of Biaryls Fused to a Seven-Membered Sultam. Eur. J. Org. Chem. 2015, 2015, 7885-7891.

(5) Rieger, E.; Alkan, A.; Manhart, A.; Wagner, M.; Wurm, F. R. Sequence-Controlled Polymers via Simultaneous Living Anionic Copolymerization of Competing Monomers. Macromol Rapid Commun. 2016, 37, 833-839.

(6) Ian C. Stewart, C. C. L., Robert G. Bergman, and F. Dean Toste. Living RingOpening Polymerization of N-Sulfonylaziridines: Synthesis of High Molecular Weight Linear Polyamines. J. Am. Chem. Soc. 2005, 127, 17616-17617.

(7) Rieger, E.; Gleede, T.; Weber, K.; Manhart, A.; Wagner, M.; Wurm, F. R. The living anionic polymerization of activated aziridines: a systematic study of reaction conditions and kinetics. Polym. Chem. 2017, 8, 2824-2832. 